\title{
Understanding peer effects: on the nature, estimation, and channels of peer effects
}

\author{
Feld, Jan ; Zölitz, Ulf
}

\begin{abstract}
This paper estimates peer effects in a university context where students are randomly assigned to sections. While students benefit from better peers on average, low-achieving students are harmed by high-achieving peers. Analyzing students' course evaluations suggests that peer effects are driven by improved group interaction rather than adjustments in teachers' behavior or students' effort. Building on Angrist's research, we further show that classical measurement error in a setting where group assignment is systematic can lead to a substantial overestimation of peer effects. However, when group assignment is random-like in our setting - peer effect estimates are biased toward zero.
\end{abstract}

DOI: https://doi.org/10.1086/689472

Posted at the Zurich Open Repository and Archive, University of Zurich ZORA URL: https://doi.org/10.5167/uzh-147244

Journal Article

Published Version

Originally published at:

Feld, Jan; Zölitz, Ulf (2017). Understanding peer effects: on the nature, estimation, and channels of peer effects. Journal of Labor Economics, 35(2):387-428.

DOI: https://doi.org/10.1086/689472 


\title{
Understanding Peer Effects: On the Nature, Estimation, and Channels of Peer Effects
}

\author{
Jan Feld, Victoria University of Wellington
}

\section{Ulf Zölitz, Behavior and Inequality Research Institute (briq), $I Z A$, and Maastricht University}

\begin{abstract}
This paper estimates peer effects in a university context where students are randomly assigned to sections. While students benefit from better peers on average, low-achieving students are harmed by highachieving peers. Analyzing students' course evaluations suggests that peer effects are driven by improved group interaction rather than adjustments in teachers' behavior or students' effort. Building on Angrist's research, we further show that classical measurement error in a setting where group assignment is systematic can lead to a substantial overestimation of peer effects. However, when group assignment is random - like in our setting — peer effect estimates are biased toward zero.
\end{abstract}

\section{Introduction}

The promise of the peer effects literature is to provide policy makers with advice that can be used to increase overall performance by simply reorga-

We would like to thank Joshua Angrist, Sandra Black, Lex Borghans, Harold Cuffe, Gigi Foster, Andries de Grip, Monique de Haan, Thomas Dohmen, Andreas Dzemski, David Figlio, Bart Golsteyn, Daniel Hamermesh, Randi Hjalmarsson, Olivier Marie, Julie Moschion, Derek Stemple, Benedikt Vogt, participants at various seminars and conferences, and especially Nicolás Salamanca for helpful discussions and comments. We further thank Joël Castermans, Sanne Klasen, and Kim

[Journal of Labor Economics, 2017, vol. 35, no. 2]

(C) 2017 by The University of Chicago. All rights reserved. 0734-306X/2017/3502-0005\$10.00

Submitted July 12, 2014; Accepted March 17, 2016; Electronically published January 30, 2017 
nizing peer groups. When looking at the by now substantial number of published articles that estimate peer effects in education, it becomes apparent that the literature has not yet delivered on this promise. This can be seen, for example, in the recent review by Sacerdote (2011), who shows that size, and even the sign of peer effects estimates, notably differ between and even within primary, secondary, and postsecondary education.

One potential reason why peer effects estimates are so varied is that there are a number of social and statistical forces that lead to similar outcomes between peers, even in the absence of causal peer effects (Manski 1993; Angrist 2014). Two well-known challenges to the identification of peer effects are the selection and reflection problems. The selection problem states that peer groups are usually formed endogenously and that it is empirically difficult to distinguish peer effects from selection effects. The reflection problem states that it is impossible to distinguish the effect of peers on the individual from the effect of the individual on peers if both are determined simultaneously. A number of recent peer effects studies (Lyle 2007; Carrell, Fullerton, and West 2009; Duflo, Dupas, and Kremera 2011; Carrell, Sacerdote, and West 2013) have convincingly addressed the selection and reflection problems by studying peer effects in a setting where students are exogenously assigned to peer groups and by using pre-treatment characteristics as measures for peer ability. Even these estimates, however, might be biased due to a mechanical relationship between the measures of own and peer ability, as described in Angrist (2014). The nature of this bias is still poorly understood.

In the analytical part of this paper, we build on Angrist (2014) to analyze the role of measurement error in the estimation of peer effects. We show that classical measurement error-which is usually associated with attenuation bias - can lead to overestimation of peer effects. We find that the size and direction of this bias depends on the true underlying peer effect and the group assignment mechanism. We show, both analytically and using Monte Carlo simulations, that in settings where peers are randomly assigned, classical measurement error will only lead to attenuation bias. With systematic student assignment, however, measurement error can lead to substantial overestimation of peer effects. This bias is distinct from selection bias.

Besides estimation bias, the large heterogeneity in peer effect estimates might reflect that peer effects are generated by mechanisms that are highly

Schippers from the School of Business and Economics (SBE) at Maastricht University Scheduling Department, Sylvie Kersten from the SBE Exams Office, and Jeannette Hommes and Paul Jacobs from the Educational Research and Development Department, for providing data and valuable background information. We thank Sophia Wagner for providing excellent research assistance. Contact the corresponding author, Ulf Zölitz, at zoelitz@iza.org. Information concerning access to the data used in this article is available as supplementary material online. 
context specific. Take, for example, adjustment of teachers' behavior as one potential channel of peer effects. While Duflo et al. (2011) have shown that this channel matters in Kenyan classrooms, it is irrelevant in the settings where peer groups have no common teachers, as in living communities (see Sacerdote 2001; Zimmerman 2003; Lyle 2007; Carrell et al. 2009, 2013). A better understanding of the channels that drive peer effects could lead to a better understanding about why they differ across contexts. So far, there exists only limited empirical evidence on the channels of peer effects. ${ }^{1}$

In the empirical part of this paper, we estimate peer effects in academic achievement in a setting where peers are randomly assigned to sections at the university level. The data consist of all students enrolled at the School of Business and Economics (SBE) at Maastricht University and their grades over a period of 3 years, which amount to 7,672 students and 39,813 grades. Course participants are assigned to sections, groups of 10-15 students, who spend most of their contact hours together in one classroom. Our measure of student performance is course grades. Following the standard approach in the literature, to avoid the reflection problem, we use a pre-treatment indicator of peer quality: the past grade point average (GPA) of the peers. To identify potential nonlinearities in peer effects, we estimate heterogeneous effects in terms of student and peer achievements. Finally, we use data on students' individual-level course evaluation to shed some light on which channels might be driving the observed peer effects in our setting.

Our results for the linear-in-means specification show that being assigned to a section with, on average, higher-achieving peers increases students' grades in that course by a statistically significant but small amount. A one standard deviation increase in the average peer GPA causes an increase of $1.26 \%$ of a standard deviation in student grades. This result, however, masks important heterogeneity: low-achieving students are actually harmed by high-achieving peers. Analyzing students' course evaluations, we find suggestive evidence that the main channel of the observed peer effects is improved group interaction. We find no evidence for an adjustment in teacher behavior or student effort driven by the section peer composition.

Taken together, this article makes two main contributions. First, our discussion of the role of measurement error in the estimation of peer effects sheds light on a potential threat to the identification of peer effects that has so far been poorly understood. Second, we provide clean estimates of peer effects using a large data set of randomly assigned students.

The remainder of the paper is structured as follows. Section II builds on Angrist (2014) to analyze how measurement error biases the estimation of peer effects. Section III describes the institutional environment studied and

\footnotetext{
${ }^{1}$ See, e.g., Duflo et al. (2011) for evidence on channels in primary education; Lavy, Paserman, and Schlosser (2012) in secondary education; and Booij, Leuven, and Oosterbeek (forthcoming) in postsecondary education.
} 
the assignment procedure of students into sections. Section IV discusses the data set. Section V provides evidence that the assignment to sections is random, conditional on scheduling constraints. Section VI discusses the empirical strategy and the results. Section VII investigates the underlying channels using students' course evaluations. Section VIII concludes.

\section{Measurement Error and the Estimation of Peer Effects}

In a recent overview, Angrist (2014) discusses many threats to the identification of peer effects. In particular, he shows, building on earlier work by Acemoglu and Angrist (2001), that measurement error can lead to overestimation of peer effects. ${ }^{2}$ This might seem counterintuitive since measurement error is usually associated with attenuation bias. The key problem in this context is that measurement error in own ability will automatically lead to measurement error in measured group ability because it is an aggregate of the individual ability measures. Since ability will always be measured with some error, a typical peer effects regression will thus contain two mismeasured independent variables, which makes the direction of the bias unclear. We phrase the discussion below in terms of the estimation of peer effects, but it generalizes to other settings where one independent variable is the group average of another mismeasured independent variable. ${ }^{3}$ In these settings, measurement error can lead to an upward bias in the group average coefficient.

We believe Angrist has uncovered an important source of bias that deserves further investigation, since he does not explicitly show under which assignment mechanisms an upward bias exists or how the magnitude of this bias depends on the underlying parameters. In this section, we will therefore first review Angrist's decomposition of the peer effects coefficient. Then, expanding upon this, we will show how classical measurement error can lead to overestimation of peer effects. Finally, we use Monte Carlo simulations to show how the size of this bias varies under different peer assignment regimes.

\section{A. Decomposition of the Peer Effects Estimator}

Consider the following ordinary least squares (OLS) regression model:

$$
y_{i g}=\mu+\pi_{0} x_{i}+\pi_{1} \bar{x}_{g}+\xi_{i},
$$

${ }^{2}$ See also Moffitt (2001) and Ammermueller and Pischke (2009) for a discussion on the role of measurement error in the estimation of peer effects.

${ }^{3}$ The problem we describe here for the estimation of peer effects also arises in other contexts, for example, when including both own household income and the average household income in a geographic area in the same regression. Whenever "own status" and some group average of this status are included in the same regression, measurement error can lead to upward bias in the estimated group coefficient. 
where $y_{i g}$ is the grade of student $i$ in group $g, x_{i}$ is the measure of student ability, $\bar{x}_{g}$ is the average of $x_{i}$ in group $g, \xi_{i}$ is an error term, and $E\left[\xi_{i} \mid x_{i}\right]=$ $E\left[\xi_{i} \mid \bar{x}_{g}\right]=0$. For simplicity, we will discuss group average measures of ability as opposed to the leave-out means (i.e., the group average excluding student $i$ ) as this distinction matters little econometrically. In particular, Angrist (2014) has shown that the peer effects estimator, when using leave-out means instead of group averages, differs only by a factor of $N_{g} /\left(N_{g}-1\right)$, where $N_{g}$ is the size of group $g$. Acemoglu and Angrist (2001) have shown that in this setup, the population parameter $\pi_{1}$ is equal to

$$
\pi_{1}=\phi\left(\psi_{\mathrm{IV}}-\psi_{\mathrm{OLS}}\right) \approx \psi_{\mathrm{IV}}-\psi_{\mathrm{OLS}},
$$

where $\psi_{\text {OLS }}$ is equal to the population coefficient from a bivariate regression of $y_{i g}$ on $x_{i}$ and $\psi_{\mathrm{IV}}$ is the population coefficient of ability in a two-stage least squares IV regression of $y_{i g}$ on ability using group dummies as instruments for ability. Here $\phi=1 /\left(1-R^{2}\right)$, where $R^{2}$ is the $R$-squared from the first stage of the above IV regression. ${ }^{4}$ As this $R$-squared is typically close to zero, the peer effects estimator is approximately equal to the difference between the IV and OLS estimators of grades on own ability.

One can see from equation (2) that not only peer effects but all factors that lead to a difference between $\psi_{\mathrm{IV}}$ and $\psi_{\mathrm{OLS}}$ will affect $\pi_{1}$. We will focus here on measurement error in $x_{i}$ as a plausible reason why $\psi_{\mathrm{IV}}$ and $\psi_{\text {OLS }}$ would differ even in the absence of peer effects. ${ }^{5}$ But how can measurement error lead to an overestimation of peer effects? The intuition behind this is as follows. If there is measurement error in $x_{i}$, both $\psi_{\mathrm{IV}}$ and $\psi_{\mathrm{OLS}}$ are attenuated, that is, biased toward zero. When student assignment to peer groups is systematic, $\psi_{\mathrm{IV}}$ is, in the absence of actual peer effects, less attenuated than $\psi_{\text {OLs }}$, which leads to an overestimation of peer effects. While Angrist also argues that the direction of the bias depends on the assignment mechanism, he is - probably due to the condensed nature of his overview-not explicit on why this is the case. We show this bias analytically in the next section.

\section{B. Measurement Error and Bias of $\pi_{1}$}

We model the grade data-generating process as follows:

$$
y_{i g}=\delta+\beta_{0} x_{i}^{*}+\beta_{1} \bar{x}_{g}^{*}+u_{i},
$$

where $y_{i g}$ is the grade of student $i$ in group $g, x_{i}^{*}$ is student $i$ 's latent ability, $x_{g}^{*}$ is the group average of $x_{i}^{*}$ in group $g, \delta$ is a constant, $\beta_{0}$ is the causal effect of ability on grade, and the parameter of interest, $\beta_{1}$, is the causal effect of

${ }^{4}$ Definitions of $\psi_{\text {OLS }}, \psi_{\text {IV }}$, and $R^{2}$ can be found in Appendix Section A1.1.

${ }^{5}$ Angrist further mentions weak instrument bias: if students are randomly assigned to groups an IV with a weak first stage might bias $\psi_{\text {IV }}$ toward $\psi_{\text {OLs }}$, which would bias peer effects estimates toward zero. 
group average ability on grade. We, however, only observe a noisy measure of individual ability, $x_{i}=x_{i}^{*}+\varepsilon_{i}$, where $\varepsilon_{i}$ is classical measurement error, which has a mean of zero and is independent of $x_{i}^{*}, \bar{x}_{g}^{*}$ and $u_{i}$. Measurement error in the measure of individual ability will automatically lead to measurement error in the measure of group ability, so $\bar{x}_{g}=\bar{x}_{g}^{*}+\bar{\varepsilon}_{g}$, where $\bar{x}_{g}^{*}$ and $\bar{\varepsilon}_{g}$ are the respective averages of $x_{i}^{*}$ and $\varepsilon_{i}$ in group $g$. To focus this discussion on the role of measurement error, we assume that $E\left[u_{i} \mid x_{i}^{*}\right]=E\left[u_{i} \mid \bar{x}_{g}^{*}\right]=0$, which means that if we would perfectly observe $x_{i}^{*}$ and $\bar{x}_{g}^{*}$ (i.e., if $\left.\varepsilon_{i}=0\right), \pi_{1}$ would be equal to $\beta_{1}{ }^{6} \mathrm{We}$ take equation (2) as a starting point and further decompose the peer effects estimator given the definition of variables and the data-generating process defined above. For brevity, we do the analytical stepby-step decomposition in Appendix Section A1.1, where we show that

$$
\pi_{1}=\beta_{1} \phi\left(\frac{\operatorname{Var}\left(\bar{x}_{g}^{*}\right)}{\operatorname{Var}\left(\bar{x}_{g}\right)}-\frac{\operatorname{Var}\left(\bar{x}_{g}^{*}\right)}{\operatorname{Var}\left(x_{i}\right)}\right)+\beta_{0} \phi\left(\frac{\operatorname{Var}\left(\bar{x}_{g}^{*}\right)}{\operatorname{Var}\left(\bar{x}_{g}\right)}-\frac{\operatorname{Var}\left(x_{i}^{*}\right)}{\operatorname{Var}\left(x_{i}\right)}\right)
$$

Note that $\phi$, which is equal to $1 /\left(1-R^{2}\right)$, is always larger than one and usually close to one. We define $W \equiv \operatorname{Var}\left(\bar{x}_{g}^{*}\right) / \operatorname{Var}\left(\bar{x}_{g}\right)-\operatorname{Var}\left(\bar{x}_{g}^{*}\right) / \operatorname{Var}\left(x_{i}\right)$ and $\mathrm{Q} \equiv \operatorname{Var}\left(\bar{x}_{g}^{*}\right) / \operatorname{Var}\left(\bar{x}_{g}\right)-\operatorname{Var}\left(x_{i}^{*}\right) / \operatorname{Var}\left(x_{i}\right)$ and can thus rewrite equation (4) like this:

$$
\pi_{1}=\beta_{1} \phi W+\beta_{0} \phi Q
$$

We show in Appendix Section A1.2, that without measurement error $\pi_{1}$ is equal to $\beta_{1}$. We further show that $\phi W$ will always range between 0 and 1 , and in the case of random assignment to peer groups, it will be equal to the test reliability of ability $\operatorname{Var}\left(x_{i}^{*}\right) / \operatorname{Var}\left(x_{i}\right)$. So $\phi W$ alone would only lead to an attenuation of $\pi_{1}$. To understand any potential upward bias of $\pi_{1}$, we need to understand the relationship between the ratio of variances of latent to measured group average ability $\operatorname{Var}\left(\bar{x}_{g}^{*}\right) / \operatorname{Var}\left(\bar{x}_{g}\right)$ and the ratio of variances of latent to measured individual ability $\operatorname{Var}\left(x_{i}^{*}\right) / \operatorname{Var}\left(x_{i}\right)$ in $Q$. When all individual ability measures have the same variance, we can rewrite $Q$ as (see Appendix Section A1.2):

$$
Q=\frac{\operatorname{Var}\left(x_{i}^{*}\right)}{\operatorname{Var}\left(x_{i}^{*}\right)+\frac{\operatorname{Var}\left(\varepsilon_{i}\right)}{\left(1+\left(N_{g}-1\right) \rho\right)}}-\frac{\operatorname{Var}\left(x_{i}^{*}\right)}{\operatorname{Var}\left(x_{i}^{*}\right)+\operatorname{Var}\left(\varepsilon_{i}\right)},
$$

${ }^{6}$ Note that throughout this paper we understand ability very broadly as all stable factors that influence grades, including innate ability, motivation, and access to academic resources. 
where $\rho$ is the average correlation of the distinct student abilities in group $g,{ }^{7}$ and $\operatorname{Var}\left(\varepsilon_{i}\right)$ is the variance of the measurement error.

Understanding the role of $\rho$ is central in understanding a potential upward bias in $\pi_{1}$. Importantly, when students are randomly assigned, $\rho$ will be zero, and the first and second terms of equation (6) will be equal in size. This means that $Q$ will be zero and $\pi_{1}$ will be attenuated. When students of similar ability tend to be grouped together, $\rho$ will be positive, and the first term of equation (6) will be larger than the second one; hence, $Q$ will be positive. In this case- assuming that the effect of own ability on grade $\beta_{0}$ is positive $-\pi_{1}$ will be upward biased in the absence of peer effects. Given that $\rho$ is positive, the bias will increase with the group size $N_{g}$. Note that a positive $\rho$ can also be driven by nonrandom grouping at a higher level. In our setting, for example, students' course selection is nonrandom, while assignment to sections within courses is random. Fortunately, including course fixed effects eliminates this problem by taking out the correlation of individual abilities, which is driven by systematic assignment of students to courses. ${ }^{8}$

Figure 1 visualizes our analytical findings by describing the bias as a function of the true peer effects for different values of $\rho$. To get an idea about the potential size of the bias, we use plausible values for the variables and parameters in equation (4). In particular, we set $\operatorname{Var}\left(x_{i}^{*}\right)=1$ and $\operatorname{Var}\left(\varepsilon_{i}\right)=$ $1 / 9$ to obtain a high test reliability of 0.9 , which is approximately the test reliability of the SAT for measured ability (College Board 2014). The effect of own ability on grade $\beta_{0}$ is set to 0.6 , which is approximately equal to the coefficient of the measure of own ability in our setting. We also assume that own ability, peer ability, and grade are measured with the same scale, so we can compare the magnitude of the bias with typical peer effects estimates from the review of Sacerdote (2011). For $\rho=0$, as is the case under random assignment, peer effect estimates are attenuated. For $\rho>0$, peer effects estimates are upward biased in the absence of peer effects, and this bias declines as peer effects increase.

The overall direction of the bias depends on whether the upward bias caused by $\beta_{0} \phi Q$ exceeds the attenuation bias caused by $\beta_{1} \phi W$ (see eq. [5]). The potential magnitude of the bias is substantial: in the absence of peer effects, for example, and with a group assignment that leads to $\rho=0.1$, OLS

${ }^{7}$ More specifically,

$$
\rho=\frac{1}{N_{g}\left(N_{g}-1\right)} \sum_{i \neq j}^{N_{g}} \frac{\operatorname{Cov}\left(x_{i}^{*}, x_{j}^{*}\right)}{\operatorname{Var}\left(x_{i}^{*}\right)} .
$$

${ }^{8}$ When including course fixed effects, eq. (4) holds if we replace $x_{i}$ with the residuals of a regression of $x_{i}$ on course dummies, $\tilde{x}_{i}$, throughout. Note that $\tilde{x}_{i}$ is the ability measure demeaned at the course level (see Frisch and Waugh 1933; Angrist 2014). 


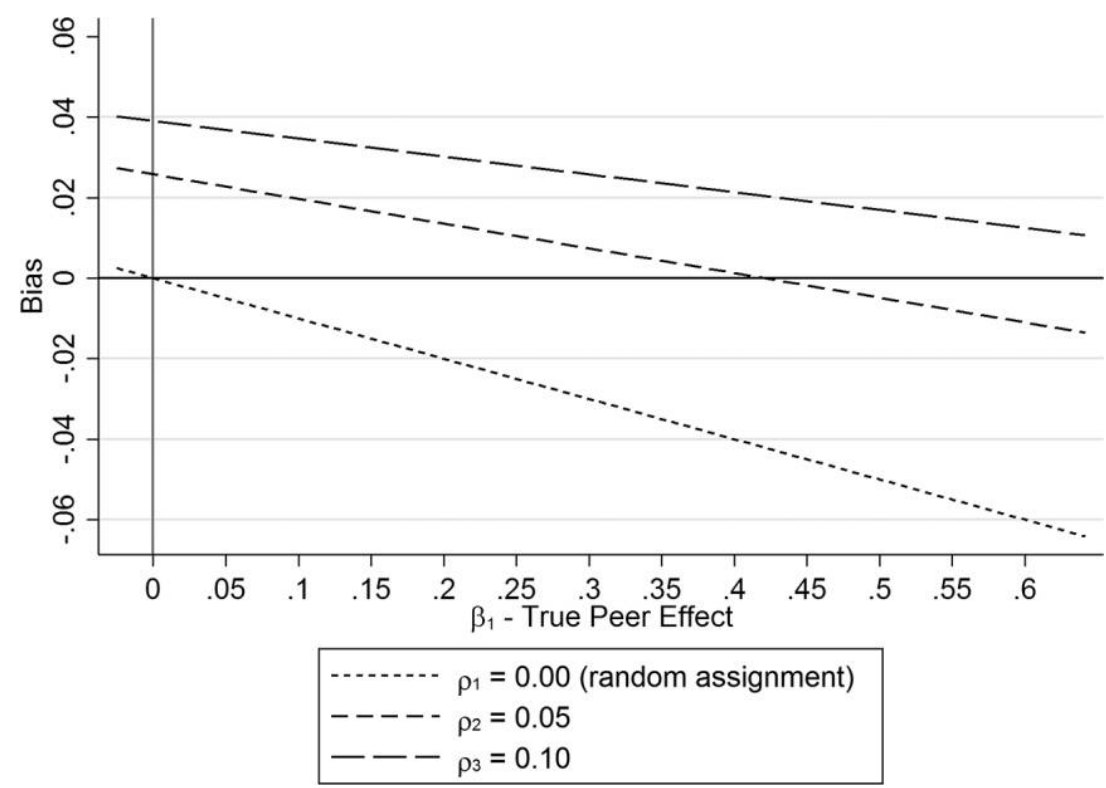

FIG. 1.-Bias as a function of the actual peer effects for different values of $\rho$. This figure is based on equation (4), with $\beta_{0}=0.6, \operatorname{Var}\left(\bar{x}_{g}^{*}\right)=1$, and $\operatorname{Var}\left(\varepsilon_{i}\right)=1 / 9$.

estimates would, on average, wrongly suggest that a one point increase in peer ability leads to an approximately 0.04 point increase in grade. This bias would be even larger for more noisy ability measures: a test reliability of 0.6 , for example, would lead to an upward bias of approximately 0.12. Differences in measurement error, degree of assortative assignment, and group size between studies can thus contribute to the large heterogeneity in peer effects estimates through the mechanism described above. For comparison, the linear in means peer effects estimates reported in the review by Sacerdote (2011) range from -0.12 to 6.8 , with a median of 0.3 . $^{9}$

\section{Results from Monte Carlo Simulations}

To confirm our analytical results, we estimate equation (3) using Monte Carlo simulations. ${ }^{10} \mathrm{We}$ use the same values for variables and parameters as for figure $1,{ }^{11}$ and we show how results vary by the student assignment

9 This refers to the peer effects estimates for primary and secondary schools reported in table 4.2 in Sacerdote (2011).

${ }^{10}$ Information concerning the Stata Do-file of this simulation is available in a zip file online.

${ }^{11}$ This means that $\beta_{0}=0.6$, ability $x_{i}^{*} \sim N(0,1)$, measurement error $\varepsilon_{1} \sim N(0,1 / 9)$, and group ability $\bar{x}_{g}^{*}$ and its measure $\bar{x}_{g}$ are calculated as laid out above. We set the error term of the model to $u_{i} \sim N(0,1)$. 
mechanism. In particular, we simulate an environment with 1,500 students, who are divided into 10 courses. Each course has 10 sections, and each section has 15 students. To see how estimates depend on the true peer effect, we set $\beta_{1}$ to 0 and 0.3 . We test three different assignment mechanisms: (i) random assignment to courses and sections, (ii) assortative course assignment and random section assignment, and (iii) random course assignment and assortative section assignment. Assortative assignment here means that students are assigned (or self-select) to peers with similar abilities. Under the random assignment, $\rho$ is approximately 0 , and assignment mechanisms 2 and 3 lead to a $\rho$ of approximately 0.1 . The assortative assignment of students to sections is based on one variable that is correlated with ability. In practice, this "assignment variable" may or may not be observable to the researcher.

Table 1 shows the average difference between estimated and actual peer effects - an indication of the estimation bias - using OLS estimation with 1,000 Monte Carlo replications. The first rows of panels A, B, and C show that peer effect estimates are unbiased in the absence of measurement error for all assignment mechanisms. This confirms that the bias discussed here is not driven by selection bias in the classical sense.

The second rows of panels $\mathrm{A}, \mathrm{B}$, and $\mathrm{C}$ show the results with measurement error. All results confirm our analytical discussion. Under random assignment to courses and sections, measurement error leads to attenuation bias (see cols. 3 and 4 of panel A). With assortative assignment, however, peer effects are overestimated (see cols. 1 and 3 of panels B and C). The size of the bias is as predicted by our analytical results: in the absence of peer effects, for example, and with course or section assignment that leads to a $\rho=$ 0.1 , the bias is approximately 0.04 (see col. 1 of panels B and C). As expected, the inclusion of course fixed effects eliminates the upward bias caused by assortative assignment to courses, and peer effects estimates are then attenuated (see col. 4 of panel B).

In many practically relevant settings, nonrandom assignment to sections (i.e., the peer group of interest) is likely to lead to a positive $\rho$. In the (rare) case where this assortative assignment is based on an observable assignment variable, controlling for this variable eliminates the potential upward bias. Estimates will again be attenuated (see col. 4 of panel C). This applies, for example, when students are tracked within schools based on past performance observable to the researcher. In this case, controlling for students' past performance will eliminate the potential upward bias by the mechanism described above.

Given that ability can only be measured with some degree of error, these findings have different implications for studies from nonexperimental and (quasi-)experimental settings. Because in nonexperimental settings assortative assignment is likely, measurement error can lead to an upward bias on top of any potential selection bias. Studies that use data from (quasi-)experimental 


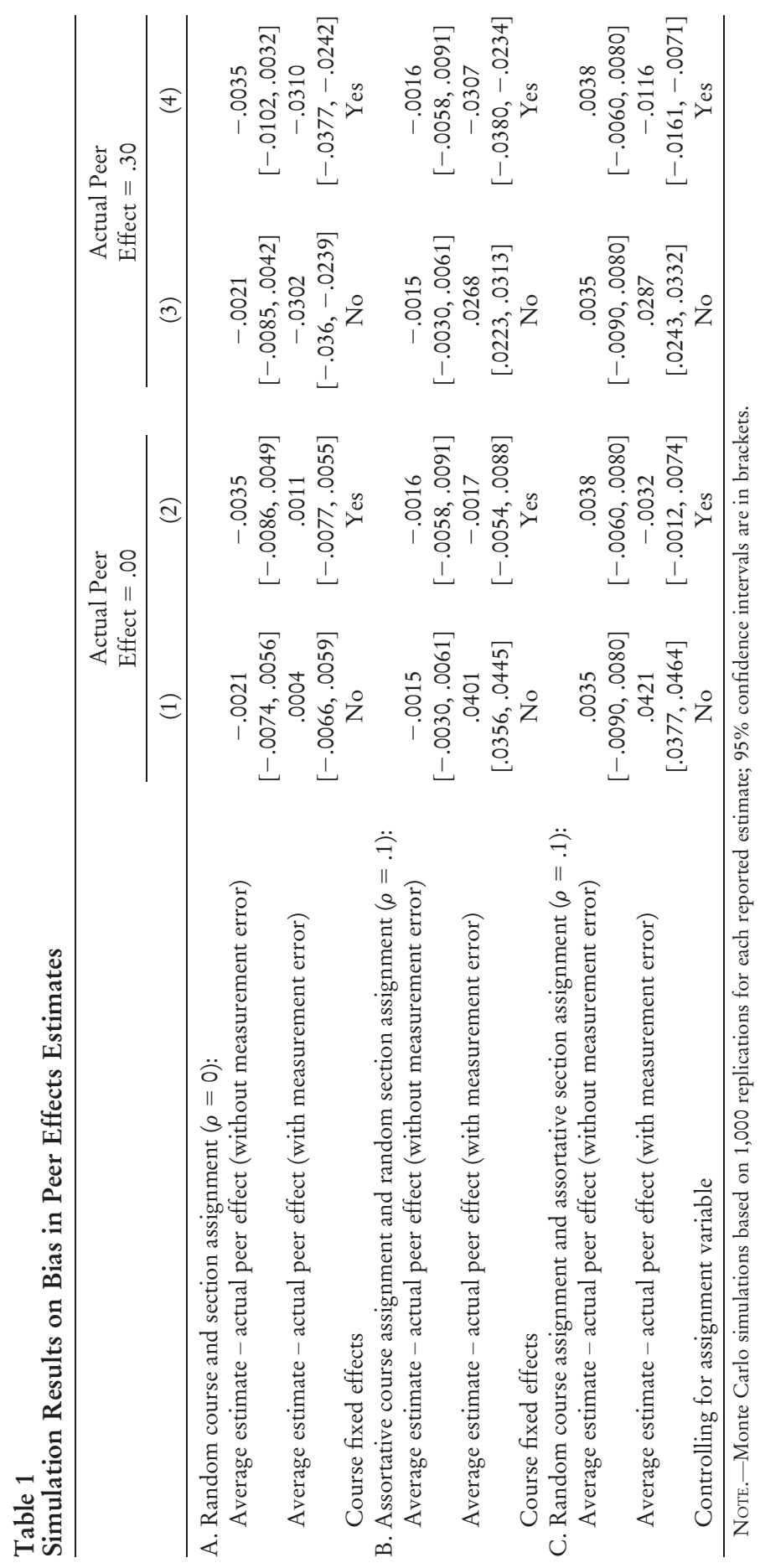

This content downloaded from 131.220.115.229 on January 29, 2018 03:51:33 AM 
settings, on the contrary, do not have these problems. It has been already well established that random assignment or systematic assignment based observables eliminates selection bias. We have now added to this by showing that in these settings measurement error will only lead to attenuation bias. In the remainder of this paper, we will present new evidence on the structure of peer effects in a setting where students were randomly assigned to university sections.

\section{Background}

\section{A. Institutional Environment}

The data we collected for this paper come from the School of Business and Economics (SBE) of Maastricht University, which is located in the south of the Netherlands. ${ }^{12}$ Currently there are approximately 4,200 students at the SBE enrolled in bachelor's, master's, and $\mathrm{PhD}$ programs. Because of its proximity to Germany, the SBE has a large German student population $(53 \%)$ mixed with students of Dutch $(33 \%)$ and other nationalities. Approximately $37 \%$ of the students are females. The academic year at the SBE is divided into four regular teaching periods of 2 months and two skills periods of 2 weeks. Students usually take two courses at the same time in the regular periods and one course in the skills period. We exclude courses in skills periods from our analysis because these are often not graded and because we could not always identify the relevant peer group. ${ }^{13}$

The courses are organized by course coordinators, mostly senior staff, and many of the teachers are $\mathrm{PhD}$ students and teaching assistants. Each course is divided into sections with a maximum of 16 students. These sections are the peer group on which we focus. The course size ranges from 1 to 638 students, and there are from 1 to 43 sections per course. The sections usually meet in two weekly sessions of 2 hours each. Most courses also have lectures that are followed by all students in the course and that are usually given by senior staff.

The SBE differs from other universities with respect to its focus on Problem Based Learning (PBL) ${ }^{14}$ The general PBL setup is that students generate questions about a topic at the end of one session and then try to answer these questions through self-study. In the next session, the findings are discussed with other students in the section. In the basic form of PBL, the teacher plays

\footnotetext{
${ }^{12}$ See also Feld, Salamanca, and Hamermesh (2016) for a detailed description of the institutional background and examination procedure at the SBE.

${ }^{13}$ In some skills courses, for example, students are scheduled in different sections but end up sitting together in the same room. Furthermore, skills courses have no exam at the end of the skill period, and in many skills courses, students do not receive a GPA-relevant grade but only a "pass" or a "fail" grade.

${ }^{14}$ See http://www.umpblprep.nl/ for a more detailed explanation of PBL at Maastricht University.
} 
only a guiding role, and most of the studying is done by the students independently. However, courses differ in the extent to which they give guidance and structure to the students, depending on the nature of the subject covered, with more difficult subjects usually requiring more guidance, and the preference of the course coordinator and teacher.

Compared to the traditional lecture system, the PBL system is arguably more group focused, because most of the teaching happens in small groups in which group discussions are the central part of the learning process. Much of the students' peer interaction happens with members of their section, either in the sessions or while completing homework and in study groups.

\section{B. Students' Course Evaluations}

Two weeks before the exam, students are invited by e-mail to evaluate the courses they are currently taking in an online questionnaire. ${ }^{15}$ Students receive up to three e-mail reminders, and the questionnaire closes before the day of the exam. Students are assured that their individual answers will not be passed on to anyone involved in the course. The teaching staff receives no information about the evaluation before they have submitted the final course grades to the examination office. ${ }^{16}$ This "double blind" procedure is implemented to avoid a situation where either of the two parties retaliates with negative feedback in the form of lower grades or evaluations. The exact length and content of the online questionnaires differ by course. The questionnaire typically contains 19-25 closed questions and two open-ended questions. For our analysis, we use the nine core questions that are assessed in most courses that allow us to investigate the effect of peers on group functioning, student effort, and teacher functioning. These questions ask students about how they perceived the instructor, how many hours they studied for the course, and about the interaction with their fellow students. Data on students' course evaluations at the individual level were provided by the Department of Educational Research and Development of the SBE. The course evaluation data are described in greater detail in Section VII.

\section{Assignment of Students to Sections}

The Scheduling Department of the SBE assigns students to sections, teachers to sections, and sections to time slots. Before each period, there is a time frame in which students can register online for the courses they want to take. After the registration deadline, the scheduler is given a list of registered students and allocates the students to sections using a computer program. About $10 \%$ of the slots in each group are initially left empty and are filled with

${ }^{15}$ For more information, see the course evaluation home page: http://iwio-sbe .maastrichtuniversity.nl/default.asp.

${ }^{16}$ After exam grades are published, teaching staff receive the results of the course evaluations aggregated at the section level. 
students who register late. ${ }^{17}$ This procedure balances the amount of late registration students over the sections. Before the start of the academic year 2010-11, the section assignment for master's courses and for bachelor's courses was conducted with the program Syllabus Plus Enterprise Timetable using the allocation option "allocate randomly" (see figure A1 in the appendix). Since the academic year 2010-11, all bachelor's sections have been stratified by nationality with the computer program SPASSAT. ${ }^{18}$ Some bachelor's courses are also stratified by exchange student status. After the assignment of students to sections, the sections are assigned to time slots, and the program Syllabus Plus Enterprise Timetable indicates scheduling conflicts. ${ }^{19}$ Scheduling conflicts arise for approximately $5 \%$ of the initial assignments. If the computer program indicates a scheduling conflict, the scheduler manually moves students between different sections until all scheduling conflicts are resolved. After all sections have been allocated to time slots, the scheduler assigns teachers to the sections. ${ }^{20}$ The section and teacher assignments are then published. After publication, the scheduler receives information on late-registering students and allocates them to the empty slots. The schedulers do not know the students nor do they observe their previous grades.

Only 20-25 students (less than 1\%) officially switch sections per period. Switching sections is possible only through a student advisor and is allowed only for medical reasons or due to a conflict with sports practice for students who are on a list of top athletes. ${ }^{21}$ Students sometimes switch their sec-

${ }^{17}$ About $5.6 \%$ of students register late. The number of late registrations in the previous year determines the number of slots that are initially left unfilled by the scheduler.

${ }_{18}$ The stratification goes as follows: the scheduler first selects all German students (who are not ordered by any observable characteristic) and then uses the option "Allocate Students set SPREAD," which assigns an equal number of German students to all classes. Then the scheduler repeats this process with the Dutch students, and the scheduler finally distributes the students of all other nationalities to the remaining spots.

${ }_{19}$ There are four reasons for scheduling conflicts: (i) the student takes another regular course at the same time; (ii) the student takes a language course at the same time; (iii) the student is also a teaching assistant and needs to teach at the same time; and (iv) the student indicated nonavailability for evening education. By default, all students are recorded as available for evening sessions. Students can opt out of this default position by indicating this in an online form. Evening sessions are scheduled from 6 p.m. to 8 p.m., and approximately $3 \%$ of all sessions in our sample are scheduled for this time slot.

${ }^{20}$ Approximately $10 \%$ of teachers indicate time slots when they are not available for teaching. They do so before they are scheduled, and the signature of the department chair is required.

${ }^{21}$ We do not have a record for these students and therefore cannot exclude them. However, section switching in these rare cases is mostly due to conflicts with medical and sports schedules and therefore unrelated to section peers. 
tion unofficially when they have extra appointments. This type of switching is usually limited to one session, and students rarely switch sections permanently. ${ }^{22}$

There are some exceptions to this general procedure, which are described in Appendix Section A3. After removing these exceptions, neither students nor teachers, and not even course coordinators, have any influence on the composition of the sections in our estimation sample.

\section{Data}

We obtained data for all students taking courses at the SBE during the academic years 2009-10, 2010-11, and 2011-12. Scheduling data were provided by the Scheduling Department of the SBE. The scheduling data include information on section assignment, the allocated teaching staff, and the day of the week and the time of day the sessions took place, as well as a list of late registrations for our sample period. In total, we have 7,672 students, 395 courses, 3,703 sections, and 39,813 grades in our estimation sample. Panel A of table 2 provides an overview of courses, sections, and students in the different years. ${ }^{23}$

The data on student grades and student background, such as gender, age, and nationality, were provided by the Examinations Office of the SBE. The Dutch grading scale ranges from 1 to 10 , with 5.5 being the lowest passing grade.

Figure 2 shows the distribution of final grades in our estimation sample. The final course grade is often calculated as the weighted average of multiple graded components, such as the final exam grade, a participation grade, a presentation grade, or a midterm paper grade. ${ }^{24}$ The graded components and their respective weights differ by course, with most courses giving most of the weight to the final exam grade. If the final course grade of a student after taking the final exam is lower than 5.5, the student fails the course and has the option of taking a second and third attempt at the exam. We observe final grades after each attempt separately. For our analysis, we use only the final grade after the first exam attempt as an outcome measure because firstand second-attempt grades are not comparable. ${ }^{25}$ For the construction of

${ }^{22}$ It is difficult to obtain reliable numbers on unofficial switching. From our own experience and consultation with teaching staff, we estimate that session switching happens in less than $1 \%$ of the sessions, and permanent unofficial class switching happens for less than $1 \%$ of the students.

${ }^{23}$ We refer to each course-year combination as a separate course, which means that we treat a course with the same course code that takes place in 3 years as three distinct courses.

${ }^{24}$ We excluded 36 courses in which part of the final grade might have consisted of group-graded components from the estimation sample (see Sec. IV.C).

${ }_{25}$ The second-attempt exam usually takes place 2 months after the first exam. 


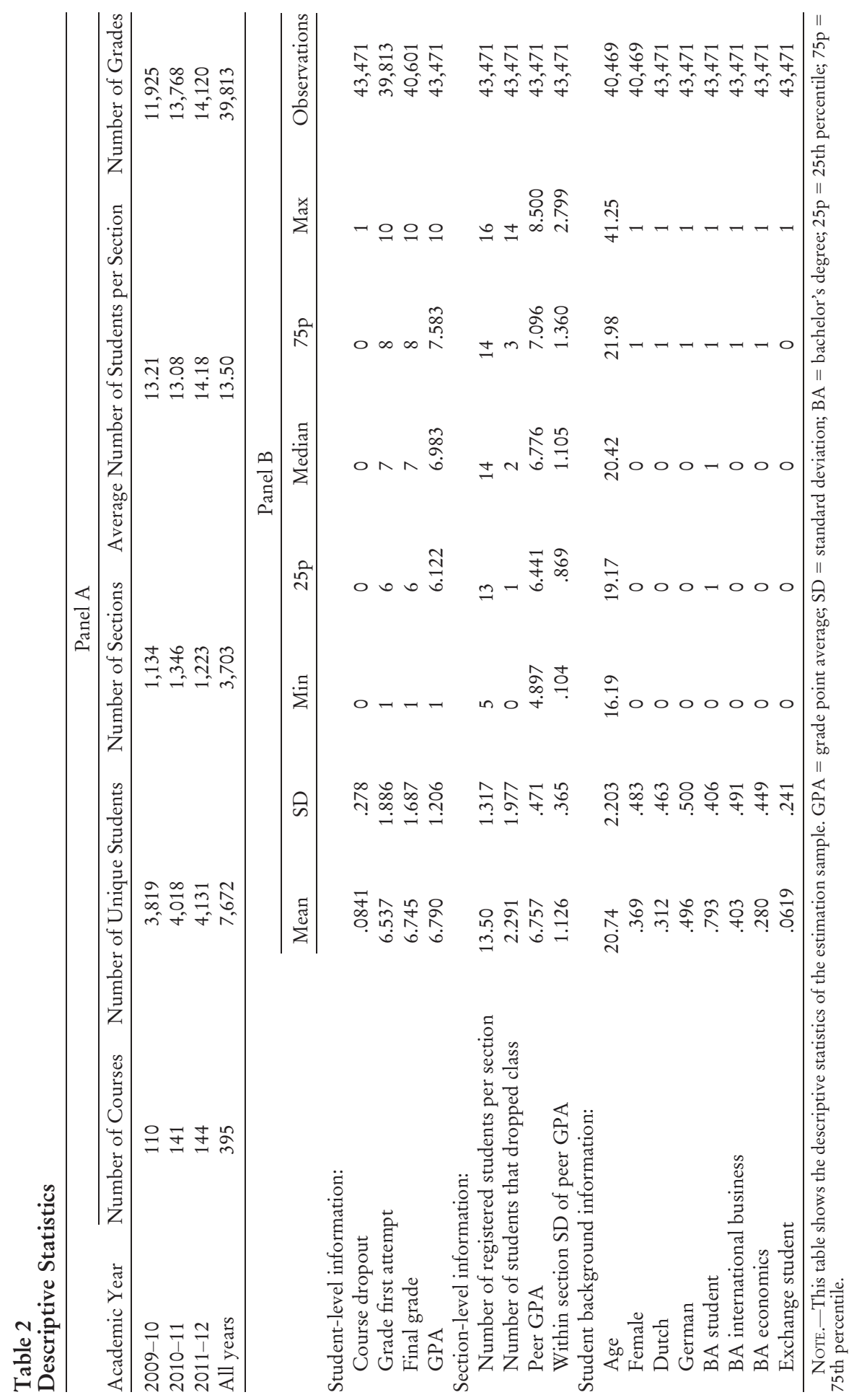

This content downloaded from 131.220.115.229 on January 29, 2018 03:51:33 AM

All use subject to University of Chicago Press Terms and Conditions (http://www.journals.uchicago.edu/t-and-c). 


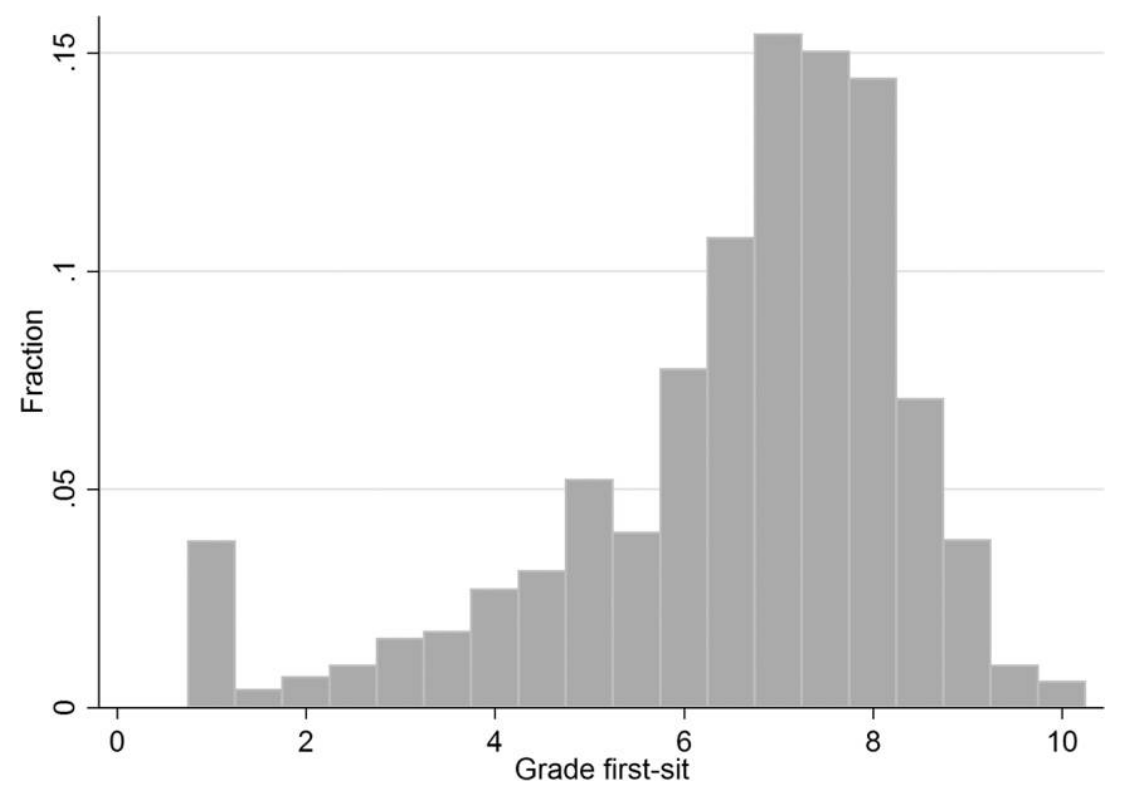

FIG. 2.-Distribution of grades after the first examination. A color version of this figure is available online.

the student's GPA (grade point average), we use the final grades after the last attempt. $^{26}$

Panel B of table 2 shows some descriptive statistics for our estimation sample. Our sample contains 43,471 student course registrations. Out of these, 3,658 (8\%) dropped out of the course during the course period. We therefore observe 39,813 course grades after the first attempt. The average course grade after the first attempt is 6.54. Approximately one-fifth of the graded students obtain a course grade lower than 5.5 after the first attempt and therefore fail the course. The average final course grade (including grades from second and third attempts) is 6.75, and the average GPA is 6.79. Figure 3 shows the distribution of the GPAs based on final grades.

The peer GPA is the section average GPA excluding the grades of the student of interest. Figure 4 shows the distribution of peer ability, measured as the average GPA of all other students in the section.

\section{Test for Random Assignment of Students to Sections}

The scheduling procedure that we describe in Section III.C shows that section assignment is random conditional on scheduling constraints.

${ }^{26}$ We decided to use the GPA calculated from final grades because this is closer to the popular understanding of GPA. 


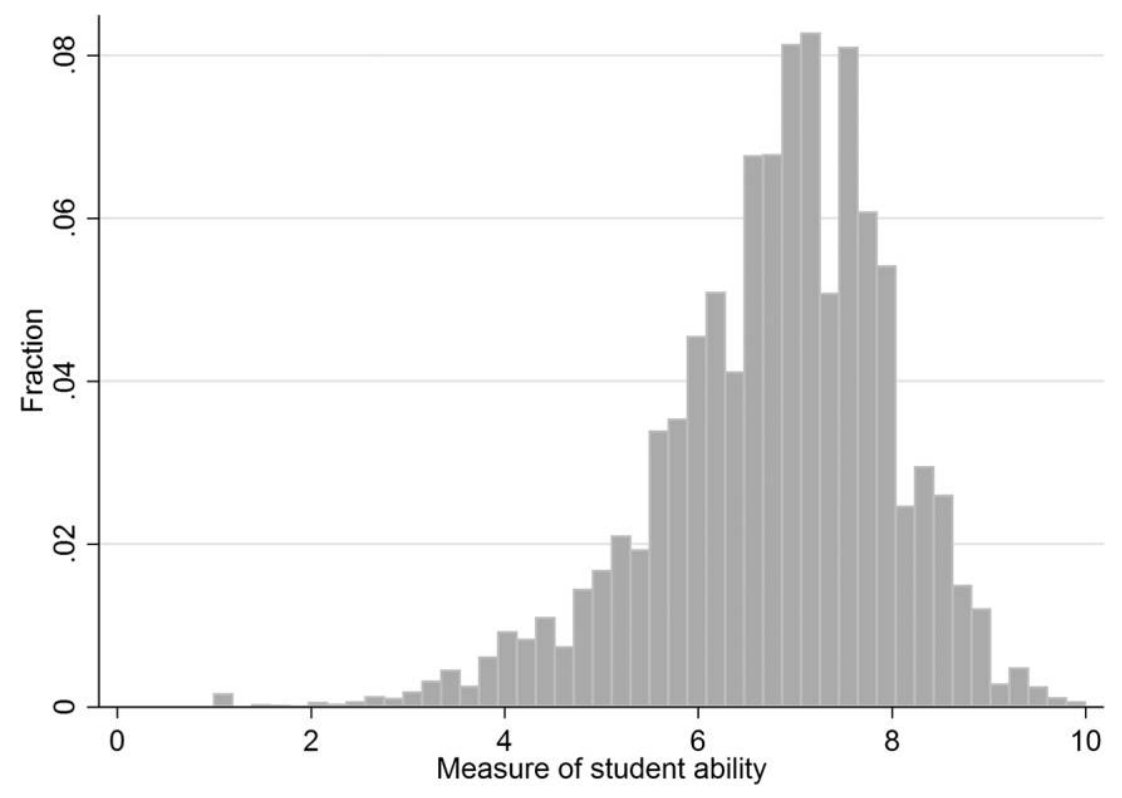

FIG. 3.-Distribution of student GPA. A color version of this figure is available online.

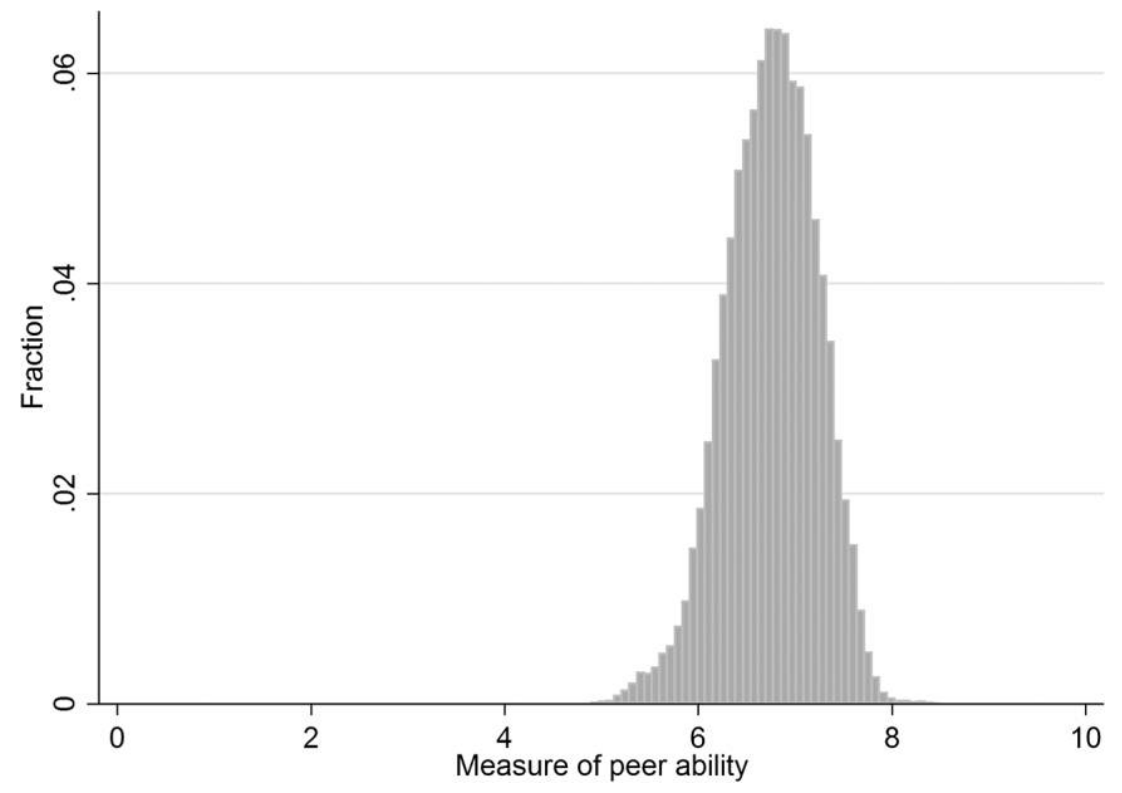

FIG. 4.-Distribution of peer GPA. A color version of this figure is available online. 
Nevertheless, we test whether section assignment has the properties that one would expect under random assignment. In particular, we would like to test whether the section-level (pre-treatment) peer GPA significantly predicts students' own (pre-treatment) GPA when controlling for course fixed effects, scheduling, and balancing indicators. ${ }^{27}$ However, such a test is complicated by an artificial negative correlation between own and peer GPA that exists even under random assignment. The intuition behind this problem is that students cannot be assigned to themselves. High-ability students therefore draw peers from a pool of lower-ability peers, which creates an artificial negative correlation between own and peer ability. This was first described by Guryan, Kroft, and Notowidigdo (2009), who show that one can correct for this negative correlation by including the leave-me-out-mean of peer ability at the level at which the randomization takes place. We follow their proposed solution by including the average GPA of all peers at the course level.

Table 3 shows the results of this randomization test with different sets of controls. In all specifications, peer GPA at the section level is not significantly related to the student's own GPA. This confirms that the assignment to sections has the properties that one would expect under random assignment.

\section{Empirical Strategy and Results}

\section{A. Empirical Strategy}

We use the following model to estimate the effect of peers on grades:

$$
Y_{i g t}=\beta_{1} \mathrm{GPA}_{i, t-1}+\beta_{2} \overline{\mathrm{GPA}}_{g-i, t-1}+\gamma^{\prime} Z_{i g t}+\varepsilon_{i g t} .
$$

The dependent variable $Y_{\text {igt }}$ is the grade of student $i$, in a course-specific section $g$, at time $t$; GPA ${ }_{i, t-1}$ is the past GPA of student $i$; and $\overline{\mathrm{GPA}}_{g-i, t-1}$ is the average past GPA of all the students in the section excluding student $i$; $Z_{i g t}$ is a vector of additional controls; and $\varepsilon_{i g t}$ is an error term. In all specifications, $Z_{\text {igt }}$ consists of dummies for day of the week and time of the day of the sessions, German, Dutch, exchange student status, late registration status, and year-course-period fixed effects. ${ }^{28}$ In other specifications, we also include other course fixed effects - fixed effects for the other course taken at the same time-and teacher fixed effects. ${ }^{29}$ Note that $\mathrm{GPA}_{i, t-1}$ and

${ }^{27}$ See Appendix Section A4 for an alternative randomization test that reaches the same conclusion.

${ }^{28}$ For some sections, the time and day of the sessions were missing. We include separate dummies for these missing values.

${ }^{29}$ Other course fixed effects are only defined for students who take up to two courses per period. In only $1.5 \%$ of the cases, students were scheduled for more than two courses, and these students drop out of our sample when we include other 
Table 3

Randomization Test of Section Assignment

\begin{tabular}{lcccc}
\hline & \multicolumn{4}{c}{ Own GPA } \\
\cline { 2 - 5 } & $(1)$ & $(2)$ & $(3)$ & $(4)$ \\
\hline Standardized average peer GPA & -.0023 & -.0023 & -.0048 & -.0053 \\
& $(.0086)$ & $(.0086)$ & $(.0088)$ & $(.0088)$ \\
Course FE & Yes & Yes & Yes & Yes \\
Scheduling controls & No & No & Yes & Yes \\
Parallel course FE & No & Yes & No & Yes \\
$R^{2}$ & .422 & .422 & .423 & .441 \\
Observations & 43,471 & 43,471 & 43,471 & 43,471 \\
\hline
\end{tabular}

NoTE.-The dependent variable is the standardized own GPA (grade point average) from all previous courses. FE = fixed effects; GPA = grade point average. Following Guryan, Kroft, and Notowidigdo (2009), all models control for the average peer GPA at the course level. All regressions include German, Dutch, exchange student status, and late registration status. Scheduling controls include dummies for day and time of the sessions. Parallel course fixed effects are fixed effects for the courses taken at the same time. Robust standard errors clustered at the course level are in parentheses.

$\overline{\mathrm{GPA}}_{g-i, t-1}$ might measure own and peer ability with some error. ${ }^{30}$ This might bias our peer effects estimates through the mechanisms described in Section II. Since group assignment is random at the section level and since we include year-course-period fixed effects, this will lead to an attenuation of peer effects. Including stratification controls and teacher fixed effects should increase the precision but not affect the size of the estimates. Conceptually, including scheduling controls and other course fixed effects should pick up all leftover nonrandom variation in section assignment that is due to conflicting schedules. To allow for correlations in the outcomes of students within each course, we cluster the standard errors at the courseyear-period level. We standardized $Y_{i g t}, \mathrm{GPA}_{i, t-1}$ and $\overline{\mathrm{GPA}}_{g-i, t-1}$ to have a mean of zero and a standard deviation of one over the estimation sample to simplify the interpretation of the coefficients.

\section{B. Linear-in-Means Results}

Before we show estimates of peer effects on grades, we check whether peer GPA is related to course dropouts. The course dropout rate is only $8 \%$ at the SBE. OLS regressions, which we omit for brevity, show that neither average peer GPA nor the other peer GPA variables we use when estimating heterogeneous effects significantly predict course dropout. We therefore do not worry about selection bias when interpreting peer effects estimates on grades.

course fixed effects. Teacher fixed effects are fixed effects of the first teacher assigned to a session.

${ }^{30}$ Further, note that the precision of own and peer achievement estimates increases with tenure when $\mathrm{GPA}_{i, t-1}$ and $\overline{\mathrm{GPA}}_{g-i, t-1}$ are calculated with more past grades. This means that we would expect any bias from measurement error to decrease with students' tenure. 
Table 4

Baseline Estimates: Linear-in-Means

\begin{tabular}{lcccc}
\hline & \multicolumn{4}{c}{ Standardized Grade } \\
\cline { 2 - 5 } & $(1)$ & $(2)$ & $(3)$ & $(4)$ \\
\hline Standardized peer GPA & $.0108^{*}$ & $.0114^{*}$ & $.0121^{* *}$ & $.0126^{* *}$ \\
Standardized GPA & $(.006)$ & $(.006)$ & $(.005)$ & $(.006)$ \\
& $.5606^{* * *}$ & $.5605^{* * *}$ & $.5623 * * *$ & $.5622^{* * *}$ \\
Observations & $(.016)$ & $(.016)$ & $(.016)$ & $(.016)$ \\
$R^{2}$ & 39,813 & 39,813 & 39,813 & 39,813 \\
Course FE & .432 & .441 & .448 & .457 \\
Staff FE & Yes & Yes & Yes & Yes \\
Other course FE & No & Yes & No & Yes \\
\hline
\end{tabular}

NOTE.-The dependent variable is the standardized course grade. All specifications include dummies for day of the session, time of the session, German, Dutch, exchange student status, and late registration status. Other course fixed effects refer to the course that students are taking at the same time. FE = fixed effects; GPA = grade point average. Robust standard errors clustered at the course-year-period level are in parentheses.

$* p<.10$.
$* p<<.05$.
$* * p<.01$.

Table 4 shows the results of OLS regressions with the standardized grade as the dependent variable. The table shows that being assigned to section peers with a higher GPA causes higher course grades. The coefficient of standardized peer GPA is small but statistically significant in all models. The inclusion of teacher fixed effects and other course fixed effects hardly changes the effect size or its standard errors. The reported estimate in the most complete specification in column 4 shows that being assigned to peers with a one standard deviation higher GPA increases the student's grade by, on average, $1.26 \%$ of a standard deviation. The results are very similar when we define own and peer GPA solely based on first-year grades (see table A3 in the appendix). In terms of the Dutch grading scale, this estimate means that, for example, an increase of peer GPA from 6.5 to 7.0 is associated with a grade increase from 6.50 to 6.523 , a small and economically insignificant effect. It follows from our discussion in Section II that measurement error leads to attenuation of our estimator, and this attenuation is proportional to the test reliability of ability. To get a rough idea of the unattenuated coefficient, we can divide the coefficient by the split-half correlation of GPA, 0.72 , an estimator of the test reliability. ${ }^{31}$ This increases the estimate to $1.75 \%$ of a standard deviation.

To explore heterogeneous effects, we extend the baseline analysis by additionally including interaction terms of peer GPA with dummies of course type or student gender. Table 5 shows the results of this analysis, where we

${ }^{31}$ In order to calculate the split-half correlation, we randomly assigned all past grades of a student into two groups and constructed two GPAs based on these subgroups. The split-half correlation is the correlation of these ability measures. 
Table 5

Linear-in-Means Estimates with Course Type and Gender Interactions

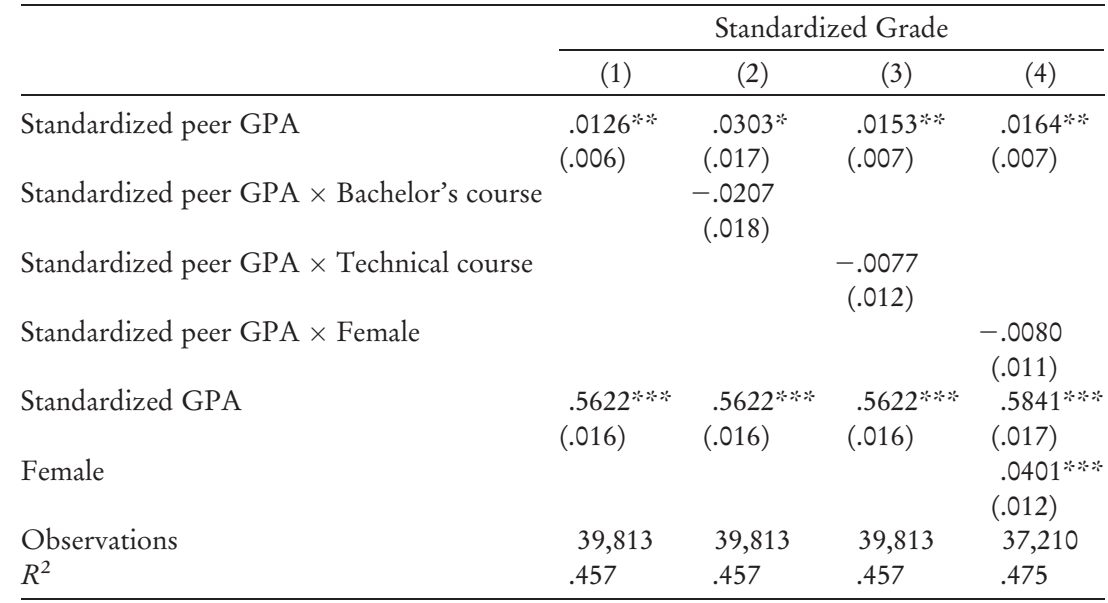

NOTE.-The dependent variable is the standardized course grade. All specifications include dummies for day of the session, time of the session, German, Dutch, exchange student status, and late registration status, as well as fixed effects for courses, fixed effects for other courses taken at the same time, and teacher fixed effects. FE = fixed effects; GPA = grade point average. Robust standard errors clustered at the courseyear-period level are in parentheses.

$* p<.10$.

$* x<.05$.

include the baseline results of table 4, column 4, in column 1 for comparison. Column 2 shows that peer effects estimates are larger for master's compared to bachelor's courses, although the difference is not statistically significant. Previous studies have found that peer effects differ between technical and nontechnical subjects. While Carrel et al. (2009) and Brunello, De Paola, and Scoppa (2010) find larger peer effects in technical subjects, Arcidiacono et al. (2012) find larger peer effects in nontechnical subjects. ${ }^{32}$ To test whether peer effects in our settings differ by course technicality, we classified a course as "technical" if at least one of the following words appeared in the course description: math, mathematics, mathematical, statistics, statistical, theory focused. Doing this, we categorized $31 \%$ of the courses as "technical." Column 3 shows that peer effects estimates are a little bit smaller in technical courses, but this difference is not statistically significant. Column 4 shows that estimated peer effects are somewhat larger for males, but again this difference is not statistically significant.

${ }^{32}$ Brunello et al. (2010) compare peer effects estimates in hard science and social science majors. Carrell et al. (2009) compare peer effects in math and science with humanities and social science courses. Arcidiacono et al. (2012) compare peer effects in humanities, social sciences, hard sciences, and mathematics, and they find larger effects for humanities and social sciences. 


\section{Heterogeneity by Own and Peer GPA}

The specifications in tables 4 and 5 are linear-in-mean, which implicitly assumes that all students are linearly affected by the mean GPA of their peers. Previous studies, however, have shown that peer effects are likely heterogeneous with respect to both student and peer achievement (Burke and Sass 2013; Carrell et al. 2013). We test for these two sources of heterogeneity simultaneously by estimating a two-way interaction model similar to those of Burke and Sass (2013) and Carrell et al. (2013). To do this, we classify students as high, middle, and low GPA based on whether their GPA is in the top, middle, or bottom third of the course GPA distribution, respectively. We then calculate for each section the fraction of peers with high GPA and low GPA and include interactions of students' own type (high, middle, and low GPA) with the fraction of high- and low-GPA peers in the model we estimate. The coefficient High GPA $\times$ Fraction of high GPA peers, for example, can be interpreted as showing how high-GPA students are affected by increasing the fraction of high-GPA peers in the section while keeping the fraction of low-GPA peers constant. Put differently, the coefficient shows how high-GPA students are affected if middle-GPA peers (the reference group) are replaced with high-GPA peers.

Table 6 shows the coefficients of these six interactions. Overall, the estimated effects are small in magnitude: for example, the largest coefficient, Low GPA $\times$ Fraction of low-GPA peers, suggests that an increase of $20 \%$ in low-GPA peers, which is equivalent to replacing three out of 15 middleGPA peers with low-GPA peers, decreases the grade of a low-GPA student by $2.63 \%$ of a standard deviation. The results for high- and middle-GPA students are in line with the linear-in-mean model: high- and middle-GPA students are positively affected by high-GPA peers and negatively affected by low-GPA peers. The results for low-GPA students, however, are noticeably different. The point estimate suggests that low-GPA students are negatively affected by high-GPA peers. They are also negatively affected by peers from their own GPA group-low-GPA peers. The effect of increasing the fraction of high-GPA peers is significantly different for low-GPA students compared to high- and middle-GPA students. To visualize the heterogeneous results, we plot the coefficients of the interactions in table 6 in figure 5. It shows that although peer effects seem to increase linearly with peer GPA for high- and middle-GPA students, the effect first increases and then decreases for low-GPA students.

These estimates are qualitatively different from the pre-treatment findings of Carrell et al. (2013), who exploit random assignment, which suggested that in particular low-achieving students benefit from high-achieving peers. This result, however, was not robust to an intervention in which lowachieving students were assigned to squadrons with a large fraction of highachieving peers. Contrary to the predictions of their pre-treatment findings, 
Table 6

Heterogeneous Effects

\begin{tabular}{lc}
\hline & Standardized Grade \\
\hline High GPA $\times$ Fraction of high-GPA peers & .0410 \\
High GPA $\times$ Fraction of low-GPA peers & $. .053)$ \\
& $-.1047 * *$ \\
Middle GPA $\times$ Fraction of high-GPA peers & $.049)$ \\
& .0789 \\
Middle GPA $\times$ Fraction of low-GPA peers & $(.052)$ \\
& -.0332 \\
Low GPA $\times$ Fraction of high-GPA peers & $(.052)$ \\
& $-.1449 *$ \\
Low GPA $\times$ Fraction of low-GPA peers & $. .076)$ \\
& $-.1315 * *$ \\
Observations & $. .066)$ \\
$R{ }^{2}$ & 39,813 \\
$F$-statistic fraction of high peers (middle vs. low) & .461 \\
$p$-value & $5.40 * *$ \\
$F$-statistic fraction of high peers (high vs. low) & .0207 \\
$p$-value & $4.38^{* *}$ \\
$F$-statistic fraction of high peers (high vs. middle) & .0370 \\
$p$-value & .26 \\
$F$-statistic fraction of low peers (middle vs. low) & .6114 \\
$p$-value & 1.39 \\
-statistic fraction of low peers (high vs. low) & .2386 \\
$p$-value & .10 \\
$p$-statistic fraction of low peers (high vs. middle) & .7462 \\
\hline -value & 1.14 \\
\hline
\end{tabular}

\footnotetext{
NOTE.-The dependent variable is the standardized course grade. Additional controls include standardized GPA, course fixed effects, other-course fixed effects, and teacher fixed effects, as well as dummies for day of the session, time of the session, German, Dutch, exchange student status, and late registration status. Robust standard errors clustered at the course level are in parentheses. GPA = grade point average. $* p<.10$.

but in line with our results, low-achieving students were actually harmed by this intervention.

\section{Channels of Peer Effects}

The peer effects that we estimated in the previous section might be driven by a number of potential channels. Changes in the peer composition could affect achievement; for example, through better group functioning, an increase in student effort or adjustments in the teaching style of the teacher. How and in which direction these channels would influence student performance is a priori unclear: while better peers might induce students to work harder (e.g., via peer pressure, higher aspirations, or social norms), 

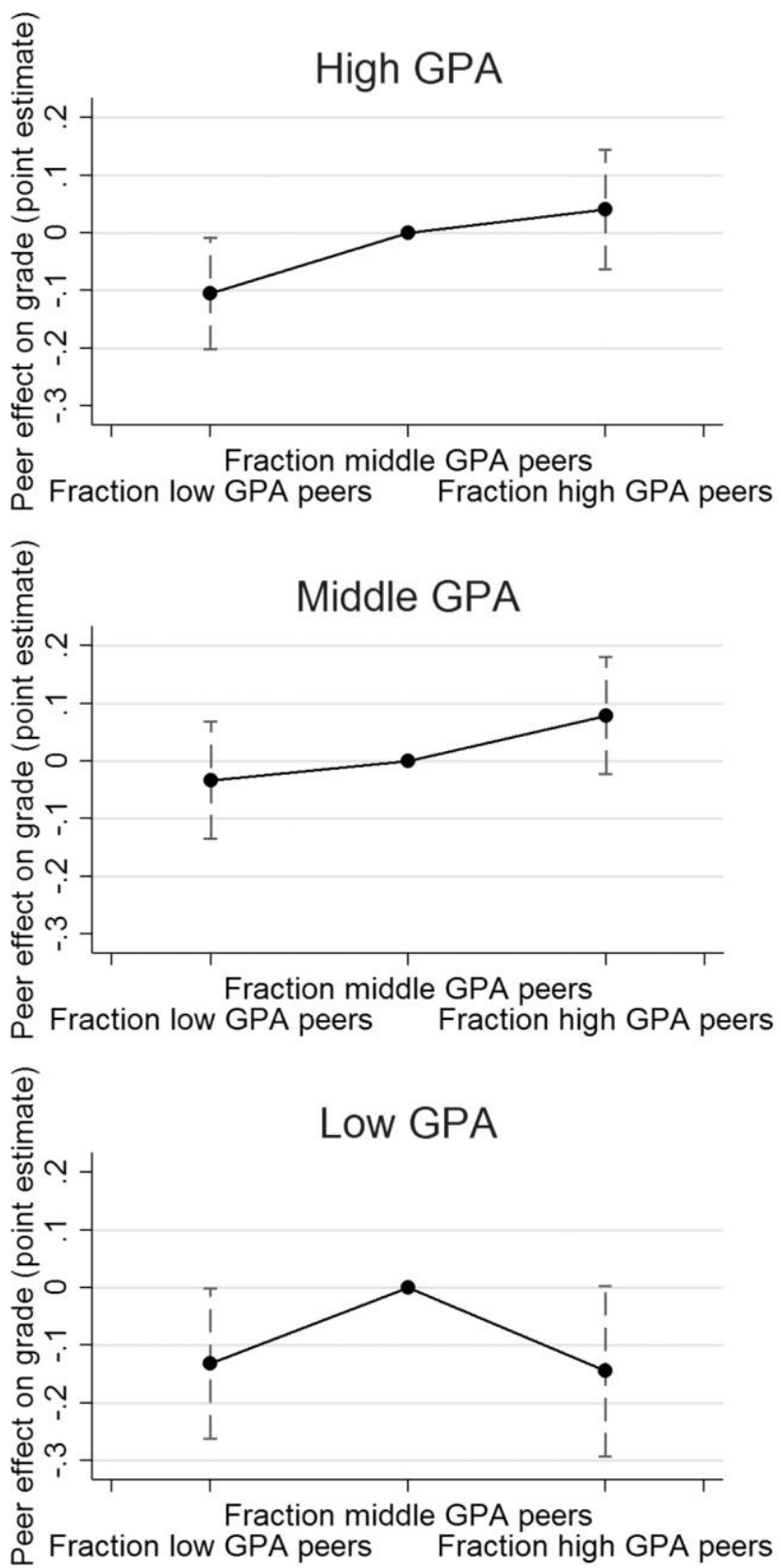

FIG. 5.-The effect of peer fractions for students with high, middle, and low GPAs. The data points in this figure are taken from table 5 using the fraction of middle-GPA peers as a reference category. 
Table 7

Evaluation Item, Answering Scales, and Response Rates

\begin{tabular}{|c|c|c|c|}
\hline Item Domain & Item Wording & $\begin{array}{l}\text { Answer } \\
\text { Scale }\end{array}$ & $\begin{array}{c}\text { Response Rate } \\
\text { Conditional on } \\
\text { Participation (\%) }\end{array}$ \\
\hline 1. Group interaction & My tutorial group has functioned well. & $1-5$ & 94.1 \\
\hline 2. Group interaction & $\begin{array}{l}\text { Working in tutorial groups with my } \\
\text { fellow-students helped me to better } \\
\text { understand the subject matters of } \\
\text { this course. }\end{array}$ & $1-5$ & 93.5 \\
\hline 3. Self-study hours & $\begin{array}{l}\text { How many hours per week on the av- } \\
\text { erage (excluding contact hours) did } \\
\text { you spend on self-study (presenta- } \\
\text { tions, cases, assignments, studying }\end{array}$ & & \\
\hline & literature, etc.)? & $0-80$ & 92.8 \\
\hline 4. Teacher functioning & $\begin{array}{l}\text { Evaluate the overall functioning of your } \\
\text { tutor in this course with a grade. }\end{array}$ & $1-10$ & 93.5 \\
\hline 5. Teacher functioning & $\begin{array}{l}\text { The tutor sufficiently mastered the } \\
\text { course content. }\end{array}$ & $1-5$ & 93.6 \\
\hline 6. Teacher functioning & $\begin{array}{l}\text { The tutor stimulated the transfer of } \\
\text { what I learned in this course to other } \\
\text { contexts. }\end{array}$ & $1-5$ & 93.4 \\
\hline 7. Teacher functioning & $\begin{array}{l}\text { The tutor encouraged all students to } \\
\text { participate in the (tutorial) group } \\
\text { discussions. }\end{array}$ & $1-5$ & 93.0 \\
\hline 8. Teacher functioning & $\begin{array}{l}\text { The tutor was enthusiastic in guiding } \\
\text { our group. }\end{array}$ & $1-5$ & 93.5 \\
\hline 9. Teacher functioning & $\begin{array}{l}\text { The tutor initiated evaluation of the } \\
\text { group functioning. }\end{array}$ & $1-5$ & 91.5 \\
\hline
\end{tabular}

NотЕ.-At Maastricht University, the teaching staff member present in the classroom is referred to as the "tutor." Sections are commonly called "tutorial groups."

lower-performing students might be demotivated by much better peers and exert less effort. Regarding the teacher behavior, we would expect teachers to adjust to the classroom peer composition by altering the difficulty level of their instructions. While an instruction level closer to the own ability level might be beneficial, larger deviations are likely to be detrimental. Such a mechanism would imply that students benefit from having more peers of similar abilities. To explore some potential channels of the peer effects in our setting, we investigate how peer ability affects students' answers in the course evaluation questionnaire.

Table 7 shows the wording and answering scales of the items regarding group functioning, self-study hours, and teacher functioning. ${ }^{33}$ In our esti-

${ }^{33}$ Standard items on the course evaluation questionnaire also include items about learning material and general course evaluation. For a complete list of all the standard evaluation items and how each item relates to mean peer GPA, see table A5 in the appendix. 
mation sample, $38 \%$ of the students start filling out the questionnaire. The last column in table 7 shows that once students started the questionnaire, they answered almost all of items. Answering the course evaluation questionnaire is selective. We observe, for example, that students with higher GPAs are more likely to take part in the evaluation, and our results should be interpreted in light of this finding. We have nevertheless chosen to analyze students' course evaluation for two reasons. First, the survey response is not significantly related to peer quality as measured by mean peer GPA or to the peer GPA variables used in Section VI.C (see table A4 in the appendix). Second, the student evaluation data give us a unique insight into potential mechanisms in a way that is not available in most other studies. All results, however, should be interpreted with caution, and we interpret them as providing suggestive evidence.

For our analysis, we aggregate items in the domains of group functioning (two items) and teacher functioning (six items) by first summing all the standardized item answers and then standardizing the sum of these values in each domain so that the aggregated categories have a mean of zero and a standard deviation of one. Answers to the question about self-study hours, which we use as a measure of student effort, are left in their natural unit. We impute missing values for items that students who started filling out the questionnaire did not answer either because the question was not in their course-specific questionnaire or because they chose not to answer the question. $^{34}$

Panel A of table 8 shows that the average peer GPA affects the evaluation of the group interaction positively. A one standard deviation increase in peer GPA leads to a 0.056 standard deviation increase in evaluation of group interaction. When redoing the analysis with each of the two items separately, we find that this result is only driven by the first item (see table A 5 in the appendix). This suggests that the students notice the better group functioning but do not perceive higher benefits from it - a result that is not surprising given the small magnitude of the estimated peer effects on grades. Hours worked and teacher functioning are not significantly affected by peer GPA.

Panel B shows the results using the same specification for identifying peer effect heterogeneity as in Section VI. This model allows us to investigate if the effect of peer GPA on course evaluations is heterogeneous in terms of student and peer achievement. When comparing the different evaluation

\footnotetext{
${ }^{34}$ Conditional on answering at least one of these questions, the percentage of missing answers is between $5.9 \%$ and $9.2 \%$ depending on the item (see table 7). We apply multiple imputations by chained equations (MICE) with 10 cycles. Note that imputing missing values might bias estimates if the missing at random assumption does not hold. We therefore also report ranges of point estimates using bounding methods in table A6 in the appendix, where we assume extreme values for missing answers. We also report results without any imputations in table A7 in the appendix. Results are very similar across these different models.
} 
Table 8

The Effect of Peer Composition on Student Evaluations

\begin{tabular}{|c|c|c|c|}
\hline & $\begin{array}{l}\text { Standardized Group } \\
\text { Interaction } \\
(1) \\
\end{array}$ & $\begin{array}{l}\text { Self-Study } \\
\text { Hours } \\
(2)\end{array}$ & $\begin{array}{c}\text { Standardized Teacher } \\
\text { Functioning } \\
(3) \\
\end{array}$ \\
\hline \multicolumn{4}{|l|}{ Panel A: } \\
\hline Standardized peer GPA & $\begin{array}{l}.0561^{* * * *} \\
(.015)\end{array}$ & $\begin{array}{l}.0339 \\
(.092)\end{array}$ & $\begin{array}{l}.0017 \\
(.013)\end{array}$ \\
\hline Standardized GPA & $\begin{array}{l}-.0348 * * * \\
(.010)\end{array}$ & $\begin{array}{c}.1353 \\
(.083)\end{array}$ & $\begin{array}{l}-.0426 * * * \% \\
(.009)\end{array}$ \\
\hline Observations & 15,441 & 15,441 & 15,441 \\
\hline \multicolumn{4}{|l|}{ Panel B: } \\
\hline $\begin{array}{l}\text { High GPA } \times \text { Fraction } \\
\text { of high-GPA peers }\end{array}$ & $\begin{array}{l}.5267 * * * \\
(.131)\end{array}$ & $\begin{array}{l}-.4390 \\
(.858)\end{array}$ & $\begin{array}{l}.0839 \\
(.096)\end{array}$ \\
\hline $\begin{array}{l}\text { High GPA } \times \text { Fraction } \\
\text { of low-GPA peers }\end{array}$ & $\begin{array}{r}-.1132 \\
(.121)\end{array}$ & $\begin{array}{r}-.8487 \\
(.852)\end{array}$ & $\begin{array}{r}-.0893 \\
(.101)\end{array}$ \\
\hline $\begin{array}{l}\text { Middle GPA } \times \text { Fraction } \\
\text { of high-GPA peers }\end{array}$ & $\begin{array}{c}.2265 \\
(.139)\end{array}$ & $\begin{array}{l}-.0499 \\
(.992)\end{array}$ & $\begin{array}{l}-.0462 \\
(.124)\end{array}$ \\
\hline $\begin{array}{l}\text { Middle GPA } \times \text { Fraction } \\
\text { of low-GPA peers }\end{array}$ & $\begin{array}{l}.0202 \\
(.110)\end{array}$ & $\begin{array}{l}1.8395^{*} \\
(.962)\end{array}$ & $\begin{array}{l}.0055 \\
(.114)\end{array}$ \\
\hline $\begin{array}{c}\text { Low GPA } \times \text { Fraction } \\
\text { of high-GPA peers }\end{array}$ & $\begin{array}{l}.2659 * * \\
(.119)\end{array}$ & $\begin{array}{r}-.3977 \\
(.919)\end{array}$ & $\begin{array}{l}.0650 \\
(.114)\end{array}$ \\
\hline $\begin{array}{c}\text { Low GPA } \times \text { Fraction } \\
\text { of low-GPA peers }\end{array}$ & $\begin{array}{c}.0369 \\
(.120)\end{array}$ & $\begin{array}{c}-1.6370 * \\
(.956)\end{array}$ & $\begin{array}{l}-.0874 \\
(.114)\end{array}$ \\
\hline Observations & 15,441 & 15,441 & 15,441 \\
\hline $\begin{array}{l}F \text {-statistic joint significance } \\
\text { of peer variables }\end{array}$ & $5.60 \% * \%$ & 1.34 & .88 \\
\hline Prob $>F$ & .0000 & .2391 & .5080 \\
\hline
\end{tabular}

NotE.-The dependent variables are standardized group interaction in col. 1, self-study hours in col. 2, and standardized teacher evaluation in col. 3. All specifications include course fixed effects, other course fixed effects, and teacher fixed effects, as well as dummies for day of the session, time of the session, German, Dutch, exchange student status, and late registration status. All regressions reported in panel B also include standardized GPA (grade point average). Robust standard errors clustered at the course-yearperiod level are in parentheses. We imputed missing values as explained in footnote 40.

$* p<.10$.

$* * p<.05$
$* * 20.01$

domains, we see that the peer variables are jointly significant in explaining the evaluation of the group interaction and not jointly significant in explaining the evaluation of the teacher or the self-study hours. The results for group interaction suggest that in particular the presence of high-GPA peers matters. The point estimate suggests that a $20 \%$ increase in high-GPA peers increases high-GPA students' evaluation of the group interaction by about 0.105 standard deviations. The estimated effects of increasing high-GPA 
peers are also positive and about half the size for medium- and low-GPA students, although the effect for medium-GPA students is not quite statistically significant ( $p$-value $=.128$ ).

All in all, our results suggest that, in our setting, group interaction is the most important of the three discussed channels. Interestingly, the effect of peer quality on group interaction appears to be linear. This implies that the inverse U-shaped pattern for low-GPA students we found in Section VII is driven by other unobserved factors. We do not find evidence for adjustment of teacher behavior or student effort.

Our results are consistent with the findings of Booij et al. (forthcoming), who studied peer effects in settings similar to ours, where the peer group is defined at the section level at a Dutch University. They also find evidence for peer effects on group functioning and no evidence of peer effects on teacher functioning. Lavy et al. (2012) study the effect of the proportion of repeaters on student outcomes in secondary schools. Using student surveys they identify changes in teachers' pedagogical practices and increases in violence and classroom disruptions as important channels. Duflo et al. (2011) find in the context of Kenyan primary schools that teachers provide more effort, as measured by teacher absenteeism, when they are randomly assigned to a class of high-achieving as compared to low-achieving students. Taken together, these findings confirm the notion that the channels, which depend on the specific contexts, can create very heterogeneous peer effects.

\section{Conclusion}

This article adds to the discussion about threats to the identification of peer effects and provides empirical evidence of peer effects in higher education. In the analytical part of this paper, we have shown that measurement error can lead to substantial overestimation of peer effects in settings where peer group assignment is systematic. In settings where peer group assignment is random or based on an observable variable, however, measurement error will only lead to attenuation bias. These findings are good news for past and future peer effects studies that rely on natural random variation or exploit a perfectly observable assignment mechanism. Peer effects estimates obtained from studies with nonobservable peer group assignment mechanism have to be interpreted with particular caution since they are prone to potentially severe upward bias due to measurement error. This bias is not the same as, and may occur on top of, any potential selection bias.

In the empirical part of this paper, we have estimated peer effects in a sample where university students are randomly assigned to sections. Consistent with previous research, we find effects of average peer quality on student grades that are small in size but statistically significant. These average effects hide important heterogeneity however. While high- and middle-ability students benefit from better peers, low-ability students are harmed by their 
high-ability peers. Evidence from students' course evaluations suggests that peer effects are driven mainly by changes in group interaction and not by adjustments in teachers' behavior or students' effort.

Our nonlinear estimates suggest that it would be possible to achieve small overall gains in student performance by reorganizing peer groups. Without knowing the process that generates the observed peer effects, however, it is not clear whether this would be welfare enhancing. In principle, increased student performance can be a result of an increase in efficiency or an increase in students' or teachers' effort. An increase in student or teacher effort implies costs which should be weighed against the benefits from increased student performance. If, however, as our results suggest, the increase in students' performance is driven by better group interaction, reorganization of peer groups can lead to higher efficiency, and welfare gains could therefore be possible.

\section{Appendix}

\section{A1. Classical Measurement Error and the Estimation of Peer Effects}

\section{A1.1. Decomposing $\pi_{1}$}

We rewrite equation (2) as

$$
\pi_{1}=\frac{\psi_{\mathrm{IV}}-\psi_{\mathrm{OLS}}}{1-R^{2}}
$$

and take this as the starting point to further decompose the peer effects estimator based on the data-generating process and variables defined in Section II. Here $\psi_{\text {IV }}$ is a two-stage least squares IV estimator. The first stage of this IV regression uses group dummies as instruments for $x_{i}$, and the predicted values of this first stage are thus group averages of $x_{i}$. Therefore $\psi_{\mathrm{IV}}$ is equal to the coefficient from a bivariate regression of $y_{i g}$ on $\bar{x}_{g}$ :

$$
\psi_{\mathrm{IV}}=\frac{\operatorname{Cov}\left(\bar{x}_{g}, y_{i g}\right)}{\operatorname{Var}\left(\overline{\mathrm{x}}_{\mathrm{g}}\right)} .
$$

By substituting $y_{i g}$ with equation (3) and rearranging, we get: ${ }^{35}$

$$
\begin{aligned}
& \psi_{\mathrm{IV}}=\frac{\operatorname{Cov}\left(\bar{x}_{g},\left(\delta+\beta_{0} x_{i}^{*}+\beta_{1} \ddot{x}_{g}^{*}+u_{i}\right)\right)}{\operatorname{Var}\left(\bar{x}_{g}\right)} \\
& \psi_{\text {IV }}=\beta_{0} \frac{\operatorname{Var}\left(\bar{x}_{g}^{*}\right)}{\operatorname{Var}\left(\bar{x}_{g}\right)}+\beta_{1} \frac{\operatorname{Var}\left(\bar{x}_{g}^{*}\right)}{\operatorname{Var}\left(\bar{x}_{g}\right)} .
\end{aligned}
$$

${ }^{35}$ Note that

$$
\operatorname{Cov}\left(\bar{x}_{g}, x_{i}^{\prime \prime}\right)=\operatorname{Var}\left(\bar{x}_{g}^{\prime \prime}\right)
$$


Analogously, we can express $\psi_{\text {OLs }}$ :

$$
\psi_{\mathrm{OLS}}=\frac{\operatorname{Cov}\left(x_{i}, y_{i g}\right)}{\operatorname{Var}\left(x_{i}\right)} .
$$

By substituting $y_{i g}$ with equation (3) and rearranging, we get

$$
\begin{aligned}
& \psi_{\mathrm{OLS}}=\frac{\operatorname{Cov}\left(x_{i},\left(\delta+\beta_{0} x_{i}^{*}+\beta_{1} \bar{x}_{g}^{*}+u_{i}\right)\right)}{\operatorname{Var}\left(x_{i}\right)} \\
& \psi_{\text {OLS }}=\beta_{0} \frac{\operatorname{Var}\left(x_{i}^{*}\right)}{\operatorname{Var}\left(x_{i}\right)}+\beta_{1} \frac{\operatorname{Var}\left(\check{x}_{g}^{*}\right)}{\operatorname{Var}\left(x_{i}\right)} .
\end{aligned}
$$

The $R^{2}$ from the first stage of the above IV estimation is equal to

$$
R^{2}=\frac{\operatorname{Var}\left(\bar{x}_{g}\right)}{\operatorname{Var}\left(x_{i}\right)} .
$$

Combining all the parts and substituting them into equation (A1), we get:

$$
\begin{aligned}
& \frac{\pi_{1}=\left(\beta_{0} \frac{\operatorname{Var}\left(\ddot{x}_{g}^{*}\right)}{\operatorname{Var}\left(\bar{x}_{g}\right)}+\beta_{1} \frac{\operatorname{Var}\left(\ddot{x}_{g}^{*}\right)}{\operatorname{Var}\left(\bar{x}_{g}\right)}\right)-\left(\beta_{0} \frac{\operatorname{Var}\left(x_{i}^{*}\right)}{\operatorname{Var}\left(x_{i}\right)}+\beta_{1} \frac{\operatorname{Var}\left(\ddot{x}_{g}^{*}\right)}{\operatorname{Var}\left(x_{i}\right)}\right)}{1-\frac{\operatorname{Var}\left(\bar{x}_{g}\right)}{\operatorname{Var}\left(x_{i}\right)}} \\
& \pi_{1}=\beta_{1} \phi\left(\frac{\operatorname{Var}\left(\bar{x}_{g}^{*}\right)}{\operatorname{Var}\left(\bar{x}_{g}\right)}-\frac{\operatorname{Var}\left(\bar{x}_{g}^{*}\right)}{\operatorname{Var}\left(x_{i}\right)}\right)+\beta_{1} \phi\left(\frac{\operatorname{Var}\left(\bar{x}_{g}^{*}\right)}{\operatorname{Var}\left(\bar{x}_{g}\right)}-\frac{\operatorname{Var}\left(\ddot{x}_{i}^{*}\right)}{\operatorname{Var}\left(x_{i}\right)}\right) \\
& \pi_{1}=\beta_{1} \phi W+\beta_{1} \phi Q,
\end{aligned}
$$

where

$$
\phi=\frac{1}{1-\frac{\operatorname{Var}\left(\bar{x}_{g}\right)}{\operatorname{Var}\left(x_{i}\right)}} .
$$

\section{A1.2. Understanding the Direction of the Overall Bias}

Here we show how measurement error affects $\phi W$ and $\phi Q$.

We start by rewriting $\phi W$,

$$
\begin{aligned}
\phi W & =\frac{1}{1-\frac{\operatorname{Var}\left(\bar{x}_{g}\right)}{\operatorname{Var}\left(x_{i}\right)}} \times\left(\frac{\operatorname{Var}\left(\bar{x}_{g}^{*}\right)}{\operatorname{Var}\left(\bar{x}_{g}\right)}-\frac{\operatorname{Var}\left(\bar{x}_{g}^{*}\right)}{\operatorname{Var}\left(x_{i}\right)}\right) \\
& =\frac{\left(\frac{\operatorname{Var}\left(\bar{x}_{g}^{*}\right)}{\operatorname{Var}\left(\bar{x}_{g}\right)}-\frac{\operatorname{Var}\left(\bar{x}_{g}^{*}\right)}{\operatorname{Var}\left(x_{i}\right)}\right)}{1-\frac{\operatorname{Var}\left(\bar{x}_{g}\right)}{\operatorname{Var}\left(x_{i}\right)}} .
\end{aligned}
$$

Because 
On the Nature, Estimation, and Channels of Peer Effects

$$
1=\frac{\operatorname{Var}\left(\bar{x}_{g}^{*}\right)}{\operatorname{Var}\left(\bar{x}_{g}\right)}+\frac{\operatorname{Var}\left(\bar{\varepsilon}_{g}\right)}{\operatorname{Var}\left(\bar{x}_{g}\right)}
$$

and

$$
\frac{\operatorname{Var}\left(\bar{x}_{g}\right)}{\operatorname{Var}\left(x_{i}\right)}=\frac{\operatorname{Var}\left(\bar{x}_{g}^{*}\right)}{\operatorname{Var}\left(x_{i}\right)}+\frac{\operatorname{Var}\left(\bar{\varepsilon}_{g}\right)}{\operatorname{Var}\left(x_{i}\right)},
$$

we can further rewrite $\phi W$ as follows:

$$
\phi W=\frac{\left[\frac{\operatorname{Var}\left(\bar{x}_{g}^{*}\right)}{\operatorname{Var}\left(\bar{x}_{g}\right)}-\frac{\operatorname{Var}\left(\bar{x}_{g}^{*}\right)}{\operatorname{Var}\left(x_{i}\right)}\right]}{\left[\frac{\operatorname{Var}\left(\bar{x}_{g}^{*}\right)}{\operatorname{Var}\left(\bar{x}_{g}\right)}-\frac{\operatorname{Var}\left(\ddot{x}_{g}^{*}\right)}{\operatorname{Var}\left(x_{i}\right)}\right]+\left\langle\frac{\operatorname{Var}\left(\bar{\varepsilon}_{g}\right)}{\operatorname{Var}\left(\bar{x}_{g}\right)}-\frac{\operatorname{Var}\left(\bar{\varepsilon}_{g}\right)}{\operatorname{Var}\left(x_{i}\right)}\right\rangle} .
$$

Note that the terms in [. . .] are identical. In the absence of measurement error (i.e., if $\operatorname{Var}\left(\varepsilon_{i}\right)=0$ ), the terms in $\langle\ldots\rangle$ are equal to zero so $\phi W$ is equal to 1 . In the presence of measurement error, the denominator is larger than the numerator because $\operatorname{Var}\left(\bar{\varepsilon}_{g}\right) / \operatorname{Var}\left(\bar{x}_{g}\right)>\operatorname{Var}\left(\bar{\varepsilon}_{g}\right) / \operatorname{Var}\left(x_{i}\right)$, and therefore $0<\phi W<1$. Note that when students are randomly assigned, $\phi W$ is equal to the test reliability of ability $\operatorname{Var}\left(x_{i}^{*}\right) / \operatorname{Var}\left(x_{i}\right){ }^{36}$

Now let us have a look at $\phi Q$. If all ability measures have the same variance, we can use the formula for the variance of the mean of correlated variables to rewrite

$$
\operatorname{Var}\left(\bar{x}_{g}^{*}\right)=\frac{\operatorname{Var}\left(x_{i}^{*}\right)}{N_{g}}+\frac{N_{g}-1}{N_{g}} \rho \operatorname{Var}\left(x_{i}^{*}\right)
$$

and

$$
\operatorname{Var}\left(\bar{x}_{g}\right)=\frac{\operatorname{Var}\left(x_{i}^{*}\right)}{N_{g}}+\frac{N_{g}-1}{N_{g}} \rho \operatorname{Var}\left(x_{i}^{*}\right)+\frac{\operatorname{Var}\left(\varepsilon_{i}\right)}{N_{g}},
$$

where $N_{g}$ is the number of students in group $g$, and $\rho$ is the average correlation of the distinct student abilities in group $g .{ }^{37}$ After canceling out $N_{g}$, we can rewrite $\operatorname{Var}\left(\bar{x}_{g}^{*}\right) / \operatorname{Var}\left(\bar{x}_{g}\right)$ as follows:

${ }^{36}$ Note that under random assignment, $\operatorname{Var}\left(\bar{x}_{g}^{*}\right)=\operatorname{Var}\left(x_{i}^{*}\right) / N_{g}$ and $\operatorname{Var}\left(\bar{x}_{g}\right)=$ $\operatorname{Var}\left(x_{i}^{*}\right) / N_{g}+\operatorname{Var}\left(\varepsilon_{i}\right) / N_{g}$. Plugging these into eq. (A8) and rearranging, you can see that $\phi W=\operatorname{Var}\left(x_{i}^{*}\right) / \operatorname{Var}\left(x_{i}\right)$.

$$
\rho=\frac{1}{N_{g}\left(N_{g}-1\right)} \sum_{i \neq j}^{N_{g}} \frac{\operatorname{Cov}\left(x_{i}^{*}, x_{j}^{*}\right)}{\operatorname{Var}\left(x_{i}^{*}\right)} .
$$




$$
\frac{\operatorname{Var}\left(x_{i}^{*}\right)+\left(N_{g}-1\right) \rho \operatorname{Var}\left(x_{i}^{*}\right)}{\operatorname{Var}\left(x_{i}^{*}\right)+\left(N_{g}-1\right) \rho \operatorname{Var}\left(x_{i}^{*}\right)+\operatorname{Var}\left(\varepsilon_{i}\right)} .
$$

We can now rewrite $Q$ as follows:

$$
\begin{aligned}
& Q=\frac{\operatorname{Var}\left(x_{i}^{*}\right)+\left(N_{g}-1\right) \rho \operatorname{Var}\left(x_{i}^{*}\right)}{\operatorname{Var}\left(x_{i}^{*}\right)+\left(N_{g}-1\right) \rho \operatorname{Var}\left(x_{i}^{*}\right)+\operatorname{Var}\left(\varepsilon_{i}\right)}-\frac{\operatorname{Var}\left(x_{i}^{*}\right)}{\operatorname{Var}\left(x_{i}^{*}\right)+\operatorname{Var}\left(\varepsilon_{i}\right)} \\
& \mathbf{Q}=\frac{\left(1+\left(N_{g}-1\right) \rho\right) \operatorname{Var}\left(x_{i}^{*}\right)}{\left(1+\left(N_{g}-1\right) \rho\right) \operatorname{Var}\left(x_{i}^{*}\right)+\operatorname{Var}\left(\varepsilon_{i}\right)}-\frac{\operatorname{Var}\left(x_{i}^{*}\right)}{\operatorname{Var}\left(x_{i}^{*}\right)+\operatorname{Var}\left(\varepsilon_{i}\right)} \\
& \mathbf{Q}=\frac{\operatorname{Var}\left(x_{i}^{*}\right)}{\operatorname{Var}\left(x_{i}^{*}\right)+\frac{\operatorname{Var}\left(\varepsilon_{i}\right)}{\left(1+\left(N_{g}-1\right) \rho\right)}}-\frac{\operatorname{Var}\left(x_{i}^{*}\right)}{\operatorname{Var}\left(x_{i}^{*}\right)+\operatorname{Var}\left(\varepsilon_{i}\right)} .
\end{aligned}
$$

Without measurement error, the first and the second terms in $Q$ are equal, and thus $Q$ (and $\phi Q$ ) is equal to zero. With measurement error, the magnitude $Q$ of depends on average correlation of the distinct student abilities $\rho$ : under random assignment, $\rho$ will be equal to zero, both terms in equation (A11) will be the same, and $Q$ will be zero. If students tend to be grouped according to their ability, $\rho$ will be positive; the first term will be larger than the second term in equation (A11), and $Q$ (and $\phi Q$ ) will be positive. Given that students are systematically assigned to groups, the size of $Q$ increases with $\rho, N_{g}$, and $\beta_{0}$.

To conclude, in the absence of measurement error, $\phi W$ is equal to one and $\phi Q$ is equal to zero, so $\pi_{1}$ is equal to $\beta_{1}$. With measurement error, the sign of the overall bias depends on $\beta_{1} \phi W$ and $\beta_{0} \phi Q$. With random assignment $(\rho=0), \phi Q$ is equal to zero, and $\pi_{1}$ is attenuated. With systematic assignment $(\rho>0), \phi Q$ is positive. The overall size of the bias then depends on whether the upward bias caused by $\beta_{0} \phi Q$ is larger than the downward bias_-assuming that peer effects are positive-caused by $\beta_{1} \phi W$.

\section{A3. Exceptions to the Scheduling Procedure}

There are some exceptions to the section assignment procedure described in Section III.C. First, when the number of late registering student exceeds the number of empty spots, the scheduler creates a new section that mainly consists of late-registering students. We excluded eight late-registration sections from the analysis. ${ }^{38}$ Second, for some bachelor's degree courses, there are special sections consisting mainly of repeating students. Whether a

\footnotetext{
${ }^{38}$ Students who register late, for example, generally have a lower GPA and might be particularly busy or stressed during the period in which they registered late, which may also affect their performance. This dynamic might create a spurious relationship between GPA and grades.
} 
repeater section is created depends on the preference of the course coordinator and the number of repeat students. We excluded 34 repeater sections from the analysis. Third, in some bachelor's degree courses, students who are part of the Maastricht Research Based Learning (MARBLE) program are assigned to separate sections, where they often are assigned to a more experienced teacher. Students of this program are typically the highestperforming students of their cohort. We excluded 15 sections that consist of MARBLE students from the analysis. ${ }^{39}$ Fourth, in six courses, the course coordinator or other education staff influenced the section composition. ${ }^{40}$ We excluded these courses from our analysis. Fifth, some master's degree tracks have part-time students. Part-time students are scheduled mostly in evening classes, and there are special sections with only part-time students. We excluded 95 part-time students from the analysis. Sixth, we excluded the first-year, first-period courses of the two largest bachelor's degree programs (International Business and Economics) because in these courses only particular students, such as repeating students, have previous grades. Seventh, we excluded sections for which fewer than five students had a past GPA. For these courses, peer GPA does not reliably capture the peer quality of the students in the section. Eighth, we excluded sections with more than 16 students $(2 \%)$ because the official class size limit according to scheduling guidelines is 15, and in special cases 16 . Sections with more than 16 students are a result of room availability constraints or special requests from course coordinators. We also excluded 36 courses from the estimation sample in which part of the final grade might have consisted of group-graded components, such as joint papers or other jointly graded projects.

\section{A4. Alternative Test for Random Assignment of Students to Sections}

In the spirit of standard randomization checks in experiments, we test whether section dummies jointly predict student pre-treatment characteristics when controlling for scheduling and balancing indicators. The pre-treatment characteristics that we consider are GPA, age, gender, and student ID rank. ${ }^{41}$ For each course in our sample, we run a regression of pre-treatment characteristics on section dummies as well as scheduling and balancing controls, and we $F$-test for joint significance of the section dummies. Thus, we run

\footnotetext{
${ }^{39}$ We identified pure late registration classes, repeater classes, and MARBLE (Maastricht Research Based Learning) classes from the data. The scheduler confirmed the classes that we identified as repeater classes. The algorithm by which we identified late registration classes and MARBLE classes is available upon request.

${ }^{40}$ The schedulers informed us about these courses.

${ }^{41}$ For approximately $9 \%$ of our sample, mostly exchange students, we do not know the age, gender, and nationality. In Maastricht University, ID numbers are increasing in tenure at the university. ID rank is the rank of the ID number. We use ID rank instead of actual ID because the SBE recently added a new digit to the ID numbers, which creates a discrete jump in the series.
} 
approximately 400 regressions for each pre-treatment characteristic. Under conditional random assignment, the $p$-values of the $F$-tests of these regressions should be uniformly distributed with a mean of 0.5 (Murdoch, Tsai, and Adcock 2008). Furthermore, if students are randomly assigned to sections within each course, the $F$-test should reject the null hypothesis of no relation between section assignment and students' pre-treatment characteristics at the $5 \%, 1 \%$, and $0.1 \%$ significance levels in close to $5 \%, 1 \%$, and $0.1 \%$ of the cases, respectively.

Table A1 shows the number of cases in which the $F$-test actually rejected the null hypothesis at the respective levels. Column 1 shows the total number of course-level regressions for each pre-treatment characteristic. Column 3 shows that the actual rejection rates at the $5 \%$ level are close to the expected rejection rates under random assignment. The $F$-tests for the regressions with the dependent variables GPA and age are rejected slightly more often than $5 \%$, and the rejection rate for the dependent variables gender and ID rank are slightly less than 5\%. Columns 5 and 7 show the actual rejection rates at the $1 \%$ and $0.1 \%$ levels. Furthermore, these rejection rates as a whole are close to the expected rates under random assignment, with the exception of age, where the rejection rates are only slightly higher than we expected. Table A2 shows that the averages of the $p$-values of the $F$-tests for each characteristic are close to 0.5 . Figure A2 confirms that the $p$-values are roughly uniformly distributed. All together, we present strong evidence that section assignment in our estimation sample is random, conditional on scheduling and balancing indicators.

Table A1

Alternative Randomization Test of Section Assignment

\begin{tabular}{|c|c|c|c|c|c|c|c|}
\hline \multirow[b]{3}{*}{$\begin{array}{l}\text { Dependent } \\
\text { Variable }\end{array}$} & \multirow{3}{*}{$\begin{array}{c}\text { Total } \\
\text { Number } \\
\text { of } \\
\text { Courses } \\
\text { (1) }\end{array}$} & \multicolumn{6}{|c|}{ Joint $F$-Test Is Significant at Level: } \\
\hline & & \multicolumn{2}{|c|}{$5 \%$} & \multicolumn{2}{|c|}{$1 \%$} & \multicolumn{2}{|c|}{$10 \%$} \\
\hline & & $\begin{array}{l}\text { Number } \\
\text { Significant } \\
(2)\end{array}$ & $\begin{array}{c}\text { Percent } \\
\text { Significant } \\
\text { (3) }\end{array}$ & $\begin{array}{c}\text { Number } \\
\text { Significant } \\
(4)\end{array}$ & $\begin{array}{c}\text { Percent } \\
\text { Significant } \\
(5) \\
\end{array}$ & $\begin{array}{c}\text { Number } \\
\text { Significant } \\
\text { (6) }\end{array}$ & $\begin{array}{c}\text { Percent } \\
\text { Significant } \\
(7) \\
\end{array}$ \\
\hline GPA & 393 & 23 & 5.85 & 6 & 1.53 & 1 & .25 \\
\hline Age & 388 & 28 & 7.22 & 10 & 2.58 & 2 & .52 \\
\hline Gender & 376 & 12 & 3.19 & 2 & .53 & 0 & .00 \\
\hline ID rank & 393 & 18 & 4.59 & 4 & 1.02 & 2 & .51 \\
\hline
\end{tabular}

NOTE.-This table is based on separate ordinary least squares regressions with past GPA, age, gender, and ID rank as dependent variables. GPA = grade point average. The explanatory variables are a set of section dummies, dummies for the other parallel course taken at the same time, and dummies for day and time of the sessions, German, Dutch, exchange student status, and late registration status. Column 1 shows the total number of separate regressions. Columns 2,4 , and 6 show in how many regressions the $F$-test rejected the null hypothesis at the $5 \%, 1 \%$, and $0.1 \%$ level, respectively. Columns 3,5 , and 7 show for what percentage of the regressions the $F$-test rejected the null hypothesis at the respective levels. Differences in number of courses are due to missing observations for some of the dependent variables. 
Table A2

Randomization Test: Mean $p$-Values

\begin{tabular}{lcc}
\hline Dependent Variable & $\begin{array}{c}\text { Total Number of Courses } \\
(1)\end{array}$ & $\begin{array}{c}\text { Mean of } p \text {-Value } \\
(2)\end{array}$ \\
\hline GPA & 393 & .499 \\
Age & 388 & .485 \\
Gender & 377 & .502 \\
ID rank & 393 & .535 \\
\hline
\end{tabular}

NoTE.-This table is based on the regressions reported in table A1. GPA = grade point average.

Table A3

Using First Year GPA as Measure of Own and Peer Ability

\begin{tabular}{lc}
\hline & Standardized Course Grade \\
\hline Standardized first year peer GPA & $.0198 * *$ \\
& $(.008)$ \\
Standardized first year GPA & $.6506 * * *$ \\
& $(.027)$ \\
Observations & 12,046 \\
$R^{2}$ & .569 \\
Course fixed effects & Yes \\
Staff fixed effects & Yes \\
Other course fixed effects & Yes
\end{tabular}

\footnotetext{
NotE.- The dependent variable is the standardized course grade. Additional controls include dummies for day of the session, time of the session, German, Dutch, exchange student status, and late registration status. Other course fixed effects refers to the course that students are taking at the same time. GPA = grade point average. Robust standard errors clustered at the course-year-period level are in parentheses.

$* * p<.05$.

$* * * 0.01$.
} 
Table A4

Determinants of Survey Response (OLS)

\begin{tabular}{|c|c|c|}
\hline & $\begin{array}{c}\text { Response } \\
\text { (1) }\end{array}$ & $\begin{array}{c}\text { Response } \\
\text { (2) }\end{array}$ \\
\hline Standardized peer GPA & $\begin{array}{c}-.0015 \\
(.004)\end{array}$ & \\
\hline High GPA $\times$ Fraction of high-GPA peers & & $\begin{array}{r}-.0033 \\
(.037)\end{array}$ \\
\hline High GPA $\times$ Fraction of low-GPA peers & & $\begin{array}{c}-.0034 \\
(.034)\end{array}$ \\
\hline Middle GPA $\times$ Fraction of high-GPA peers & & $\begin{array}{r}-.0212 \\
(.034)\end{array}$ \\
\hline Middle GPA $\times$ Fraction of low-GPA peers & & $\begin{array}{c}.0292 \\
(.037)\end{array}$ \\
\hline Low GPA $\times$ Fraction of high-GPA peers & & $\begin{array}{r}-.0181 \\
(.027)\end{array}$ \\
\hline Low GPA $\times$ Fraction of low-GPA peers & & $\begin{array}{c}-.0248 \\
(.029)\end{array}$ \\
\hline Standardized GPA & $\begin{array}{l}.0722 * * * \\
(.0038)\end{array}$ & $\begin{array}{l}.0607 * * * \\
(.0056)\end{array}$ \\
\hline$F$-statistic joined significance of peer variables & & .45 \\
\hline Prob $>F$ & & .8456 \\
\hline Number of observations & 45,332 & 45,332 \\
\hline$R^{2}$ & .104 & .104 \\
\hline
\end{tabular}

NOTE.-Both regressions include fixed effects for the course, fixed effects for the other courses taken at the same time, and teacher fixed effects. All specifications include dummies for day of the session, time of the session, German, Dutch, exchange student status, and late registration status. GPA = grade point average. Robust standard errors clustered at the course-year-period level are in parentheses.

$* * \%<<.01$. 


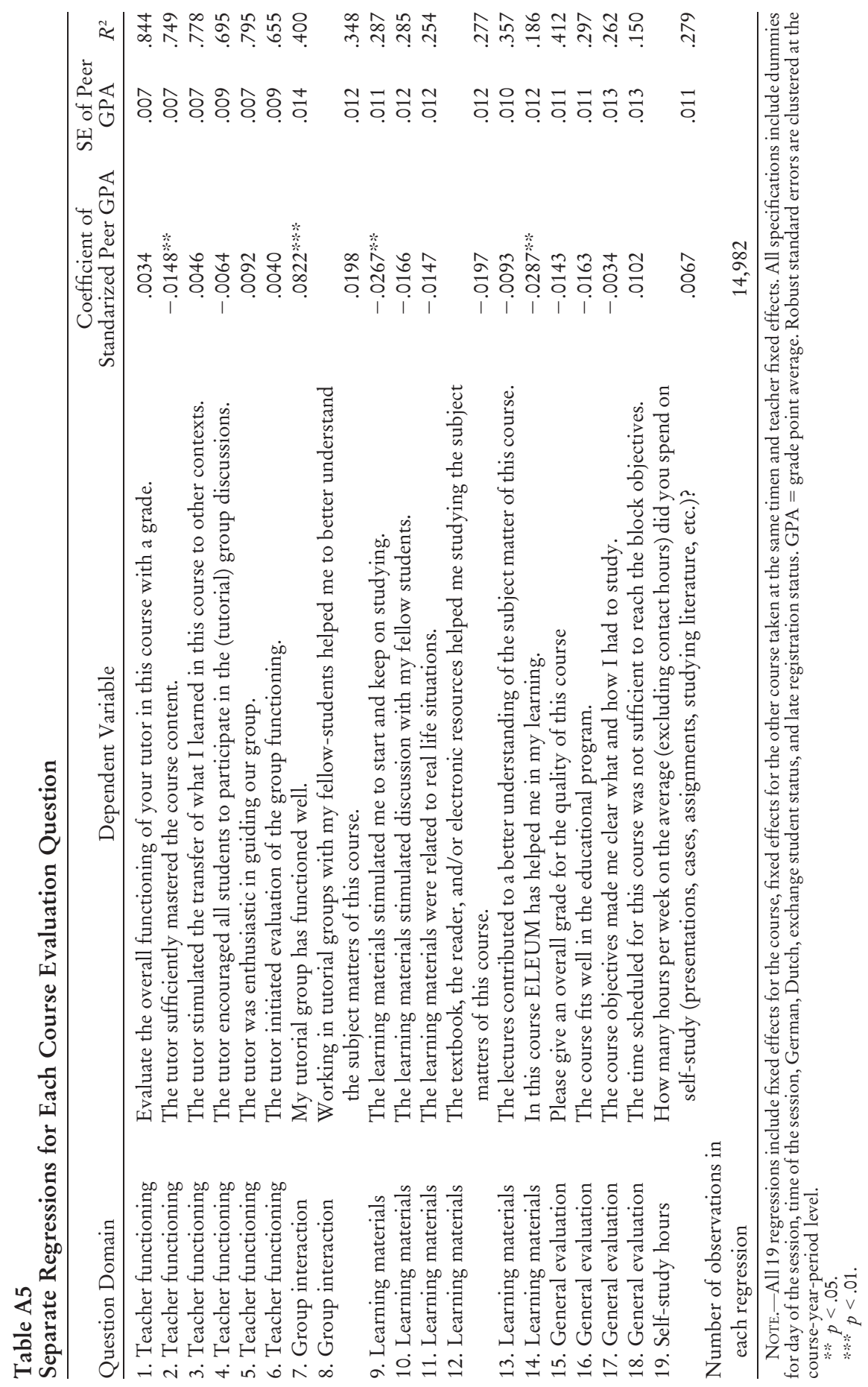




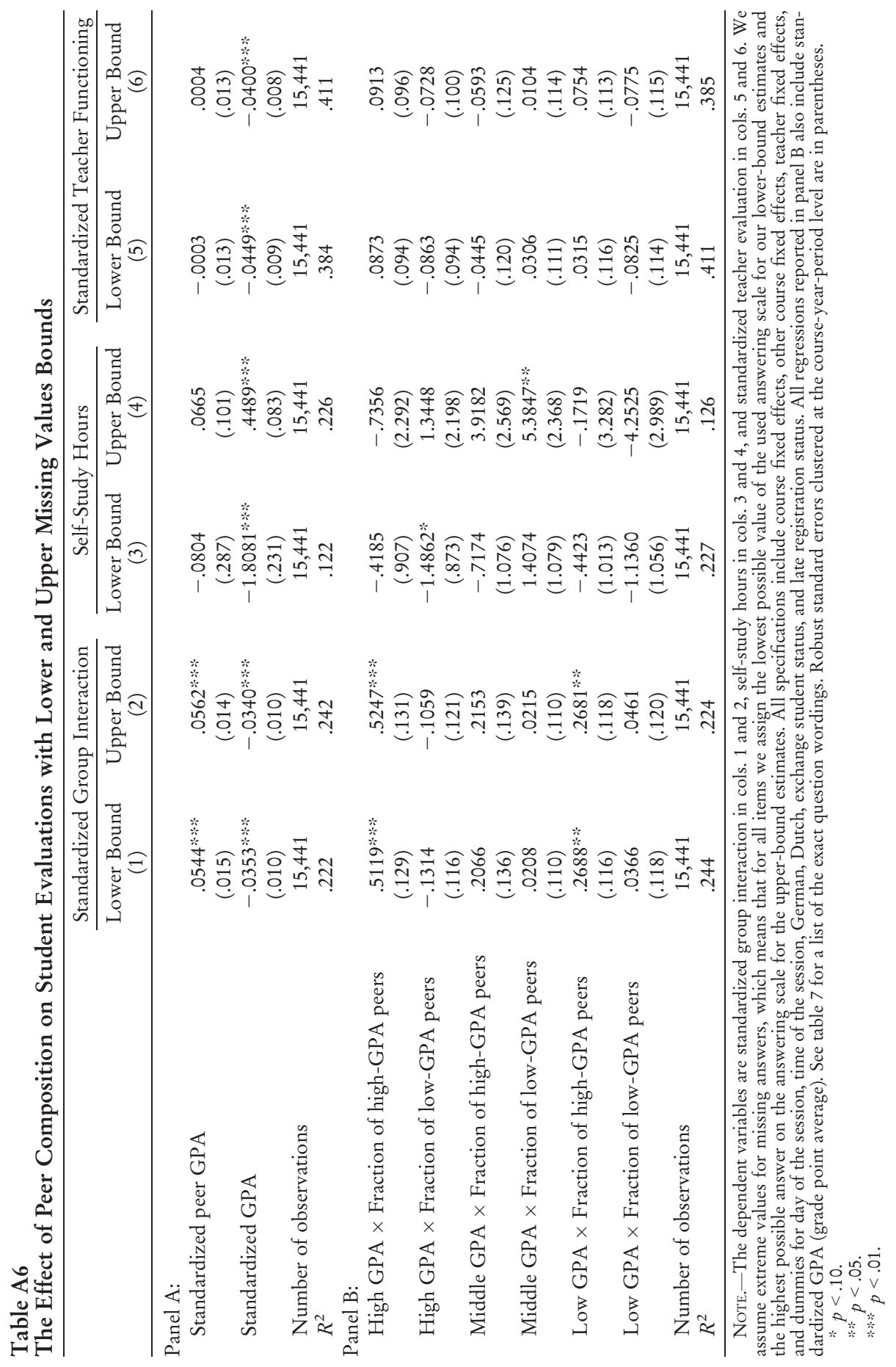


Table A7

The Effect of Peer Composition on Student Evaluations (Without Bounding or Imputations)

\begin{tabular}{|c|c|c|c|}
\hline & $\begin{array}{c}\text { Standardized Group } \\
\text { Interaction } \\
(1)\end{array}$ & $\begin{array}{l}\text { Self-Study } \\
\text { Hours } \\
(2) \\
\end{array}$ & $\begin{array}{l}\text { Standardized Teacher } \\
\text { Functioning } \\
(3)\end{array}$ \\
\hline \multicolumn{4}{|l|}{ Panel A: } \\
\hline Standardized peer GPA & $\begin{array}{l}.0550 * * * * \\
(.015)\end{array}$ & $\begin{array}{l}.0433 \\
(.092)\end{array}$ & $\begin{array}{l}.0010 \\
(.013)\end{array}$ \\
\hline Standardized GPA & $\begin{array}{l}-.0358^{* * * *} \\
(.010)\end{array}$ & $\begin{array}{l}.0530 \\
(.088)\end{array}$ & $\begin{array}{l}-.0466^{* \cdots *} \\
(.009)\end{array}$ \\
\hline & 15,285 & 15,232 & 14,654 \\
\hline Observations & .222 & .267 & .387 \\
\hline \multicolumn{4}{|l|}{ Panel B: } \\
\hline $\begin{array}{l}\text { High GPA } \times \text { Fraction of } \\
\text { high-GPA peers }\end{array}$ & $\begin{array}{l}.5297 * * * * \\
(.131)\end{array}$ & $\begin{array}{r}-.7109 \\
(.799)\end{array}$ & $\begin{array}{l}.0820 \\
(.099)\end{array}$ \\
\hline $\begin{array}{l}\text { High GPA } \times \text { Fraction of } \\
\text { low-GPA peers }\end{array}$ & $\begin{array}{r}-.1180 \\
(.120)\end{array}$ & $\begin{array}{r}-.8725 \\
(.766)\end{array}$ & $\begin{array}{r}-.0830 \\
(.101)\end{array}$ \\
\hline $\begin{array}{l}\text { Middle GPA } \times \text { Fraction o } \\
\text { high-GPA peers }\end{array}$ & $\begin{array}{r}.1881 \\
(.141)\end{array}$ & $\begin{array}{c}.0058 \\
(.991)\end{array}$ & $\begin{array}{r}-.0492 \\
(.127)\end{array}$ \\
\hline $\begin{array}{l}\text { Middle GPA } \times \text { Fraction o } \\
\text { low-GPA peers }\end{array}$ & $\begin{array}{l}.0230 \\
(.112)\end{array}$ & $\begin{array}{l}1.7851^{*} \\
(.946)\end{array}$ & $\begin{array}{l}.0410 \\
(.118)\end{array}$ \\
\hline $\begin{array}{l}\text { Low GPA } \times \text { Fraction of } \\
\text { high-GPA peers }\end{array}$ & $\begin{array}{l}.2727 * * \% \\
(.119)\end{array}$ & $\begin{array}{r}-.2952 \\
(.978)\end{array}$ & $\begin{array}{l}.0609 \\
(.119)\end{array}$ \\
\hline $\begin{array}{l}\text { Low GPA } \times \text { Fraction of } \\
\text { low-GPA peers }\end{array}$ & $\begin{array}{l}.0454 \\
(.121)\end{array}$ & $\begin{array}{r}-1.4976 \\
(.967)\end{array}$ & $\begin{array}{r}-.0665 \\
(.120)\end{array}$ \\
\hline Observations & 15,285 & 15,232 & 14,654 \\
\hline $\begin{array}{l}F \text {-statistic joined significance } \\
\text { of peer variables }\end{array}$ & .224 & .268 & .388 \\
\hline Prob $>$ F & $<.0001$ & .2169 & .5226 \\
\hline
\end{tabular}

NOTE.-All regressions include fixed effects for the course, fixed effects for the other course taken at the same time, and teacher fixed effects. The dependent variables are standardized group interaction in col. 1, self-study hours in col. 2, and standardized teacher evaluation in col. 3. All specifications include dummies for day of the session, time of the session, German, Dutch, exchange student status, and late registration status. Robust standard errors clustered at the course-year-period level are in parentheses.

$* p<.10$.

$\because p<0.05$.

$* * p<.01$. 


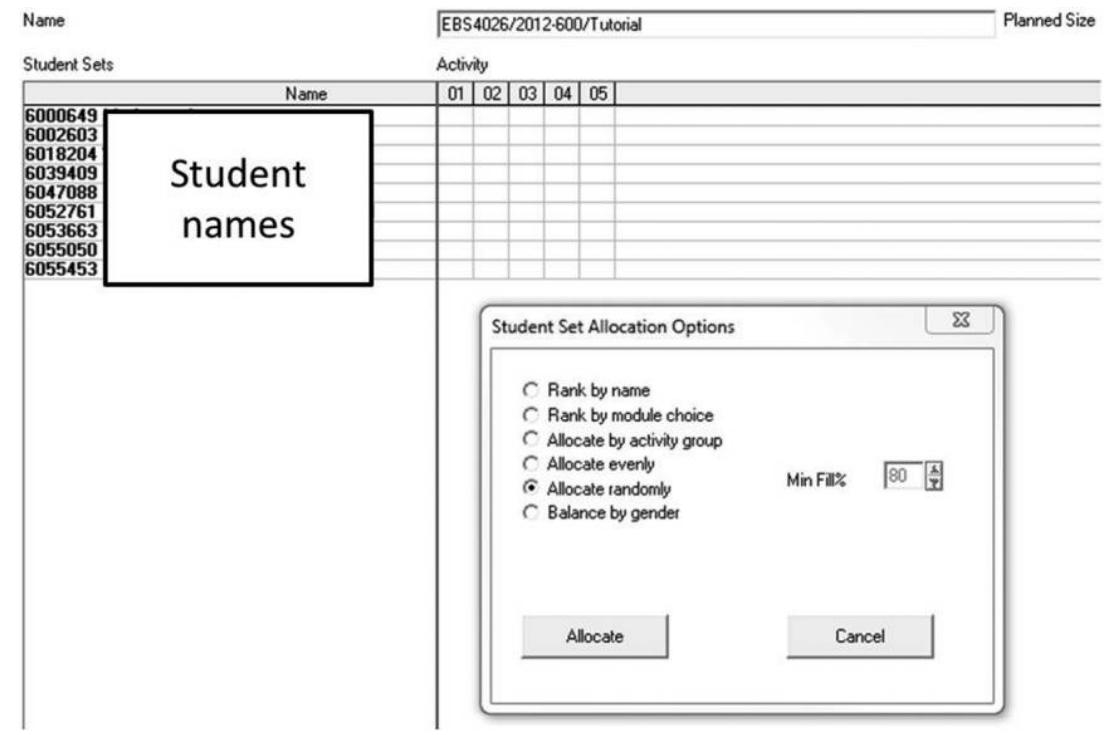

FIG. A1.-Screenshot of the scheduling program used by the SBE Scheduling Department. This screenshot shows the scheduling program Plus Enterprise Timetable@.
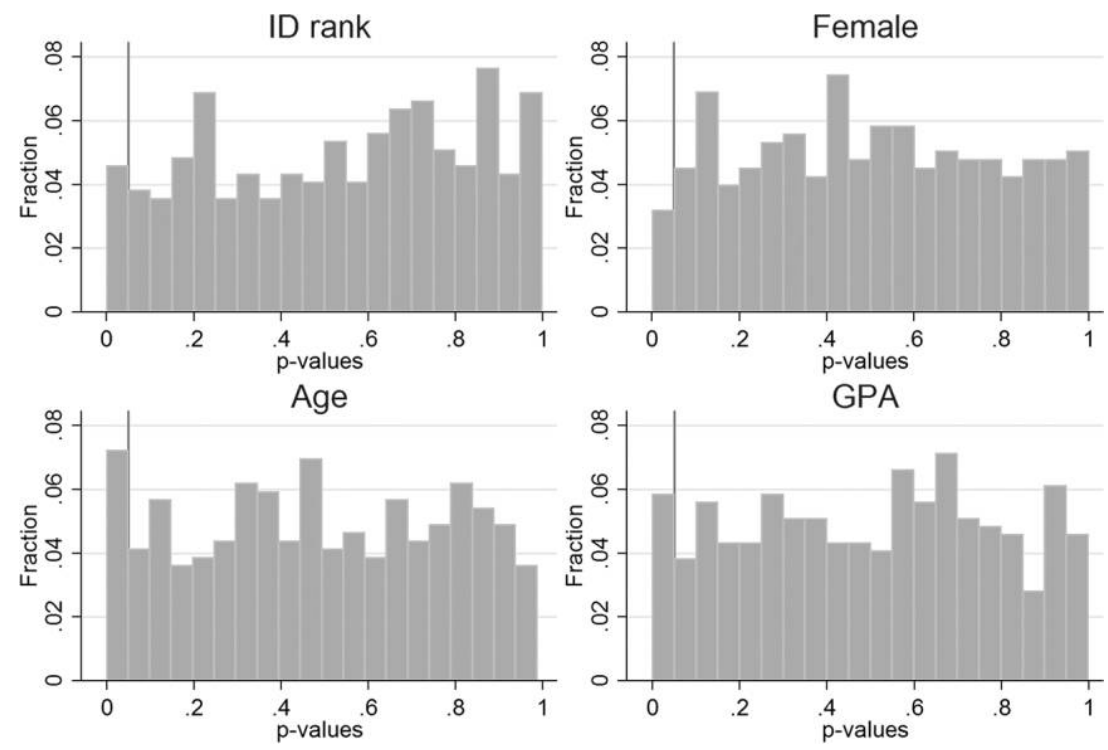

Fig. A2.-Distribution of $F$-test $p$-values as reported in table A1. These are histograms with $p$-values from all the regressions reported in table A1. The vertical line in each histogram shows the .05 significance level. A color version of this figure is available online. 


\section{References}

Acemoglu, Daron, and Joshua Angrist. 2001. How large are human-capital externalities? Evidence from compulsory-schooling laws. In NBER macroeconomics annual 2000, ed. Ben S. Bernanke and Kenneth Rogoff. Cambridge, MA: MIT Press.

Ammermueller, Andreas, and Jörn-Steffen Pischke. 2009. Peer effects in European primary schools: Evidence from the Progress in International Reading Literacy Study. Journal of Labor Economics 27, no. 3:315-48.

Angrist, Joshua D. 2014. The perils of peer effects. Labour Economics 30: 98-108.

Arcidiacono, Peter, Gigi Foster, Natalie Goodpaster, and Josh Kinsler. 2012. Estimating spillovers using panel data, with an application to the classroom. Quantitative Economics 3, no. 3:421-47.

College Board. 2014. Test characteristics of the SAT. https://secure-media .collegeboard.org/digitalServices/pdf/sat/sat-characteristics-reliability -difficulty-completion-rates-2015.pdf.

Booij, Adam S., Edwin Leuven, and Hessel Oosterbeek. Forthcoming. Ability peer effects in university: Evidence from a randomized experiment. Review of Economic Studies.

Brunello, Giorgio, Maria De Paola, and Vincenzo Scoppa. 2010. Peer effects in higher education: Does the field of study matter? Economic Inquiry 48, no. 3:621-34.

Burke, Mary A., and Tim R. Sass. 2013. Classroom peer effects and student achievement. Journal of Labor Economics 31, no. 1:51-82.

Carrell, Scott E., Richard L. Fullerton, and James E. West. 2009. Does your cohort matter? Measuring peer effects in college achievement. Journal of Labor Economics 27, no. 3:439-64.

Carrell, Scott E., Bruce I. Sacerdote, James E. West. 2013. From natural variation to optimal policy? The importance of endogenous peer group formation. Econometrica 81, no. 3:855-82.

Duflo, Esther, Pascaline Dupas, and Michael Kremer. 2011. Peer effects, teacher incentives, and the impact of tracking: Evidence from a randomized evaluation in Kenya. American Economic Review 101, no. 5:1739-74.

Feld, Jan, Nicolás Salamanca, and Daniel S. Hamermesh. 2016. Endophilia or exophobia: Beyond discrimination. Economic Journal 126, no. 594: 1503-27.

Frisch, Ragnar, and Frederick V. Waugh. 1933. Partial time regressions as compared with individual trends. Econometrica 1, no. 4:387-401.

Guryan, Jonathan, Kory Kroft, and Matthew J. Notowidigdo. 2009. Peer effects in the workplace: Evidence from random groupings in professional golf tournaments. American Economic Journal: Applied Economics 1, no. 4: 34-68.

Lavy, Victor, M. Daniele Paserman, and Analia Schlosser. 2012. Inside the black box of ability peer effects: Evidence from variation in the propor- 
tion of low achievers in the classroom. Economic Journal 122, no. 559: $208-37$.

Lyle, David S. 2007. Estimating and interpreting peer and role model effects from randomly assigned social groups at West Point. Review of Economics and Statistics 89, no. 2:289-99.

Manski, Charles F. 1993. Identification of endogenous social effects: The reflection problem. Review of Economic Studies 60, no. 3:531-42.

Moffitt, Robert A. 2001. Policy interventions, low-level equilibria, and social interactions. In Social dynamics, vol. 4, ed. Steven N. Durlauf and H. Peyton Young. Cambridge, MA: MIT Press.

Murdoch, Duncan J., Yu-Ling Tsai, and James Adcock. 2008. P-values are random variables. American Statistician 62, no. 3:242-45.

Sacerdote, Bruce. 2001. Peer effects with random assignment: Results for Dartmouth roommates. Quarterly Journal of Economics 116, no. 2:681704.

2011. Peer effects in education: How might they work, how big are they, and how much do we know thus far? In Handbook of the economics of education, vol. 3, ed. Eric A. Hanushek, Stephen Machin, and Ludger Woessman, 249-77.

Zimmerman, David J. 2003. Peer effects in academic outcomes: Evidence from a natural experiment. Review of Economics and Statistics 85, no. 1: 9-23. 